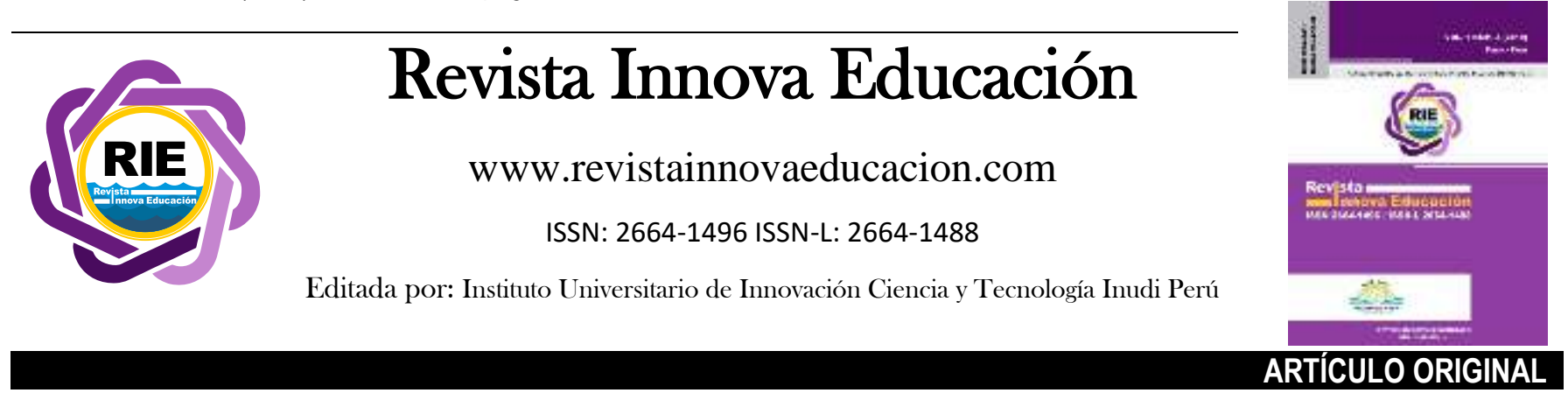

\title{
Competencias digitales en el contexto COVID 19: una mirada desde la educación
}

\author{
Digital competence in the context of COVID 19: a view from education
}

Competências digitais no contexto do COVID 19: uma visão a partir da educação

\author{
Dariel Díaz-Arce ${ }^{1}$ \\ Universidad Politécnica Salesiana-Unidad Educativa Santana, Cuenca - Quito, Ecuador \\ (D) https://orcid.org/0000-0002-5952-9916 \\ ddiaza3@est.ups.edu.ec (correspondencia) \\ Efraín Loyola-Illescas \\ Universidad Politécnica Salesiana, Cuenca - Quito, Ecuador \\ (D) https://orcid.org/0000-0002-3881-7353 \\ eloyola@ups.edu.ec
}

\begin{abstract}
DOI (Genérico)
: https://doi.org/10.35622/j.rie.2021.01.006

DOI (Documento en español) $\quad$ : https://doi.org/10.35622/j.rie.2021.01.006.es

DOI (Document in English) : : https://doi.org/10.35622/j.rie.2021.01.006.en
\end{abstract}

Recibido 12/12/2020/ Aceptado 27/01/2021 Publicado 28/01/2021

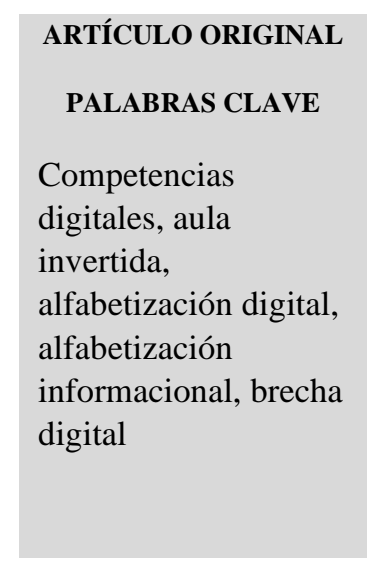

KEYWORDS
RESUMEN. Este trabajo tuvo como objetivo realizar una revisión sobre el estado del arte de las competencias digitales docentes y estudiantiles en el contexto actual de la COVID 19. Se hizo una búsqueda documental en las bases de datos Scopus, Web of Science, Scielo y Redalyc, seleccionando los artículos con criterios de inclusión y exclusión específicos. Como resultado se observó que este tema reviste una necesidad importante en el contexto actual de la pandemia, debido a sus deficiencias en el ámbito educativo. Asimismo, se muestran las diferencias de este concepto con otros como alfabetización informacional y alfabetización digital considerando sus áreas de estudio, así como las dimensiones y estándares para su implementación y evaluación. Se aportan evidencias de la importancia de la brecha digital para lograr las mismas, y de cómo se pueden desarrollar desde diferentes estrategias como el Aula Invertida. Los trabajos consultados sugieren que este modelo podría ser idóneo en el contexto de la educación actual.

\footnotetext{
ABSTRACT. This work aimed to carry out a review on the state of the art of teaching and student digital competencies in the current context of COVID 19. A documentary search was carried out in the Scopus, Web of Science, Scielo, and Redalyc databases,
}

\footnotetext{
${ }^{1}$ Docente en la Unidad Educativa Santana, Ecuador.
} 
Digital competences, flipped classroom, digital literacy, information literacy, digital divide

\section{PALAVRAS-CHAVE}

Competências

digitais, aula

invertida,

alfabetização digital, alfabetização da informação, exclusão digital selecting the articles with specific inclusion and exclusion criteria. As a result, it was observed that this topic has an important need in the current context of the pandemic, due to its deficiencies in the educational field. Likewise, the differences of this concept with others such as information literacy and digital literacy are shown considering their areas of study, as well as the dimensions and standards for their implementation and evaluation. Evidence is provided of the importance of the digital divide to achieve them, and of how they can be developed from different strategies such as the Inverted Classroom. The studies consulted suggest that this model could be ideal in the context of current education.

RESUMO. O objetivo deste trabalho foi realizar uma revisão sobre o estado da arte do ensino e das competências digitais dos alunos no contexto atual do COVID 19. Foi realizada uma pesquisa documental nas bases de dados Scopus, Web of Science, Scielo e Redalyc, selecionando artigos com critérios específicos de inclusão e exclusão. Como resultado, observou-se que este tema tem uma necessidade importante no contexto atual da pandemia, devido às suas deficiências no campo educacional. Da mesma forma, as diferenças desse conceito com outros como a alfabetização informacional e a alfabetização digital são apresentadas considerando suas áreas de estudo, bem como as dimensões e padrões para sua implementação e avaliação. São fornecidas evidências da importância da exclusão digital para alcançá-los e de como eles podem ser desenvolvidos a partir de diferentes estratégias, como a Sala de Aula Invertida. Os estudos consultados sugerem que este modelo pode ser ideal no contexto da educação atual.

\section{INTRODUCCIÓN}

En la actualidad es casi imposible separar el desarrollo de los países y naciones, de las tecnologías digitales de la información y las comunicaciones (TIC). En este sentido, los dispositivos electrónicos inteligentes, las computadoras y la hiperconectividad, se encuentran en el tope del mercado mundial a un nivel tal, que se perciben como una necesidad básica más, especialmente de interés en el campo laboral, social e individual. Por ello, se hace cada vez más importante desarrollar las habilidades y competencias básicas para el manejo seguro y eficiente de las potencialidades que éstas poseen; en otras palabras, se requiere alfabetizar a la sociedad en este lenguaje digital cada vez más universal (Ocaña-Fernández et al., 2020; Sánchez-Caballé et al., 2020).

Hasta hace unos pocos años, se reconocían como nativos digitales a aquellas personas que literalmente habían crecido con la era de las tecnologías digitales. De esta forma se creía que entendían mejor el lenguaje digital y por ende tenían mayores competencias en este aspecto. Sin embargo, la experiencia denota que estar inmersos en una sociedad digitalizada no asegura la adquisición, por sí mismos, de las competencias básicas para el manejo adecuado de estas herramientas, y que la mayoría de los trabajos sobre este tema adolecen de un fundamento empírico que los sustente (Acosta-Silva, 2017). En este sentido es donde juegan un papel primordial los sistemas educativos, promoviendo su desarrollo a través de programas de formación y entrenamiento, ya sea como parte de una asignatura o de modo transversal, tanto en docentes como en estudiantes (Cabero-Almenara \& Palacios-Rodríguez, 2020; Henriquez-Coronel et al., 2018).

A pesar de que parece un tema reciente, las competencias digitales de docentes y estudiantes se han tratado en la literatura dentro de diferentes conceptos desde hace varias décadas, relacionadas con el creciente uso de la tecnología digital y el aprendizaje usando computadoras, hasta la implementación de didácticas y modelos pedagógicos más complejos. Desde entonces, las 
investigaciones redundan en la necesidad de elevar estas competencias en los estudiantes para mejorar su desempeño académico y como habilidades para su vida futura y como profesional (Lucas, 2019; Slavova \& Garov, 2019). Asimismo, se resalta su papel inclusivo mediante la inserción de niños y jóvenes de diferentes contextos y necesidades educativas apuntando no solo a su rendimiento académico, sino también su motivación (Formichella et al., 2020; López Núñez et al., 2020). En ello incide de forma significativa las competencias docentes desde su ámbito profesional, tecnológico y pedagógico (Sánchez-Caballé et al., 2020).

En la actualidad, el tema de las competencias digitales es de vital significado en el contexto de la pandemia por COVID-19, puesto que las clases tuvieron que trasladarse hacia la virtualidad y donde los encuentros presenciales se tornan cada vez menos significativos (Sá \& Serpa, 2020). En este ámbito, la Organización de las Naciones Unidas estima que aproximadamente 1500 millones de estudiantes se vieron afectados por esta situación, exacerbándose las diferencias en la esfera educativa. Al mismo tiempo sugiere que los sistemas educativos deben dar de forma urgente un paso hacia “(...) sistemas progresistas que impartan educación de calidad para todos como una vía para lograr los Objetivos de Desarrollo Sostenible. Esto requiere inversiones en la alfabetización y la infraestructura digitales, además del reforzamiento de los vínculos entre los sectores formal e informal de la educación" (ONU, 2020). Con esto coincide otras organizaciones a nivel regional, las que reafirman que en América Latina y El Caribe también se pone en evidencia una importante brecha digital de estudiantes y docentes, lo que repercute en la calidad y aunque se implementan incontables medidas para contrarrestarlo (CEPAL \& UNESCO, 2020).

Unido a lo anterior, los estudios recientes revelan que tanto en estudiantes como en docentes el tema de las competencias digitales es prioritario, convirtiéndose en uno de los retos más importantes para los sistemas educativos y su contribución al desarrollo de una sociedad del conocimiento (Gómez-García et al., 2020; Sánchez-Caballé et al., 2020). En tal caso, se observa la necesidad de una alfabetización digital que vincule a los centros educativos con la sociedad, mejorando la adquisición de competencias digitales para el aprendizaje colaborativo, la autonomía, la comunicación efectiva, la ética y la ciudadanía digital (Dias-Trindade et al., 2020; DomingoCoscolla et al., 2020). Esto no solo contribuye al desarrollo de habilidades para la vida y el continuo aprendizaje, sino también puede ayudar a romper barreras de comunicación e integración entre las familias y la escuela (Maciá Bordalba \& Garreta Bochaca, 2018).

Algunos resultados experimentales y cuasi-experimentales sugieren que uno de los modelos pedagógicos más prometedor para desarrollar estas habilidades, es el Aula Invertida (Flipped Classroom). Su fundamento se basa en un aprendizaje activo y colaborativo, en el que se hace partícipe al estudiante como principal actor en su aprendizaje, siendo el docente más un facilitador o mediador (Gómez-García et al., 2020). Existen múltiples investigaciones que apoyan este planteamiento, aun empleando diferentes diseños metodológicos, entornos educativos y herramientas de obtención del dato primario (Koelling \& Townsend, 2019; Sosa Díaz \& Palau Martín, 2018; Tagge, 2018). Esto es de especial relevancia si se considera que también puede elevar el rendimiento académico, la satisfacción y la motivación de los estudiantes (Espada et al., 2020; Hinojo Lucena et al., 2019). A pesar de lo anterior, existen múltiples factores que pueden disminuir la eficacia de esta metodología, siendo uno de los más importante, la innegable brecha digital actual. 
Por todo lo anterior, el presente trabajo tiene como objetivo general, revisar el estado actual de las competencias digitales docente-estudiantil y cómo fomentarlas en el contexto de la educación a nivel latinoamericano y de otras regiones y su importancia durante la pandemia sobre COVID 19. Asimismo, entre sus objetivos específicos se resaltan los siguientes:

- Diferenciar los conceptos de competencias digitales de otros similares e interrelacionados como alfabetización digital y alfabetización informacional, sus áreas y dimensiones de trabajo.

- Reflexionar sobre el impacto educativo que tiene la brecha digital en el desarrollo de competencias digitales frente al nuevo panorama educativo impuesto por la COVID 19.

- Revisar el estado actual de las competencias digitales docentes y estudiantiles, considerando sus fortalezas y debilidades en el ámbito latinoamericano y de otros países.

- Describir la utilidad de diferentes estrategias para desarrollar competencias digitales en los estudiantes, haciendo énfasis en la metodología de la Clase Invertida (Flipped Classroom).

\section{MÉTODO}

Se realizó una revisión documental del estado del arte de competencias digitales, empleado las bases de datos Scopus y Web of Science, Scielo y Redalyc. Las palabras claves empleadas fueron: "Digital Skills", "Digital competence", "Digital literacy", "Information literacy", "Teacher digital competences", "Student digital competences", "Flipped Classroom", "DigCompEdu”, "Digital competences framework", las que se buscaron además con sus traducciones al español: "Habilidades digitales", "Competencias digitales", "Alfabetización digital", "Alfabetización informacional", "Competencia digital docente”, "Competencia digital estudiantil", “Aula Invertida", DigcompEdu y "Marco de competencias digitales" unidas con el operador booleano $O R$.

La selección se realizó de acuerdo al tipo de estudio y contexto realizado, con los siguientes criterios de inclusión: todos los artículos de investigación, revisiones bibliográficas y revisiones sistemáticas, que contengan al menos una de las palabras claves y sean de los últimos 5 años. Se incluyeron unos pocos artículos de trabajos publicados hace más tiempo dada su relevancia para la comprensión y argumentación del tema. Como criterios de exclusión: se descartaron los artículos que solo mencionen el término y no lo desarrollen. Además, se eliminaron los documentos que se encontraban duplicados en las diferentes bases de datos analizadas, o que no aportaron nada nuevo para el tema central de la investigación o que procedieran de fuentes menos confiables. De igual forma se descartaron los artículos a los que no se pudo acceder a formato completo aun después de escribir a los autores por una copia.

De este modo, el trabajo quedó desarrollado en cinco apartados: Las competencias digitales, la alfabetización digital e informacional: conceptos entrelazados, donde se realiza una aproximación para diferenciar conceptos relacionados; La brecha digital antes de la "Era COVID 19" en Latinoamérica y las competencias digitales docente y estudiantil, donde se realiza una reflexión sobre el tema de la brecha digital antes y durante la pandemia y su posible impacto en la 
educación desde el análisis de las competencias digitales; Las competencias digitales docentes y otro de las Competencias digitales estudiantiles, donde se aborda el concepto y el estado actual de las mismas en diferentes contextos, incluyendo el latinoamericano; se cierra con un apartado de ¿Cómo fomentar las competencias digitales en los estudiantes en el contexto actual?, donde se describen diferentes estrategias para fomentar las competencias digitales, haciendo énfasis en el modelo pedagógico y metodológico del Aula Invertida.

\section{DESARROLLO}

\section{Las competencias digitales, la alfabetización digital e informacional: conceptos entrelazados}

Existe una significativa heterogeneidad de términos que incluyen, en mayor o menor grado, a las competencias y habilidades para una sociedad inmersa en las nuevas Tecnologías de la Información y las Comunicaciones (TIC). En tal caso, tres de los más frecuentes en la literatura occidental y que se relacionan directamente con el campo de la educación son la Alfabetización Digital, las Competencias Digitales y la Alfabetización Informacional (Kolle, 2017; SánchezCaballé et al., 2020).

A pesar de lo anterior, y de que los términos no solo poseen orígenes diferentes, existe una diversidad de criterios hacia una definición específica de los mismos, creando confusiones en el ámbito científico y académico. En tal caso, la conceptualización de éstos adquiere diferente connotación si son definidos desde el diseño de políticas para su fomento, o desde la investigación científica (Spante et al., 2018). También se nota que en cierta medida se complementan entre sí, debido quizá a que hasta el momento no existe consenso sobre cuáles son las competencias o habilidades digitales básicas que deben desarrollar las personas para una verdadera sociedad digital de la información y el conocimiento.

A decir por algunos, el término alfabetización informacional o information literacy en su versión inglesa, surge a mediados de los años 70’s del siglo pasado, acuñado por el investigador Paul Zurkowski. A pesar de ello, el término sigue apareciendo confuso en algunas publicaciones, siendo la traducción para países hispanoparlantes todavía discutida, así como su definición conceptual (Vidal Ledo et al., 2016).

Con el advenimiento de las TIC y la masificación del acceso a la información y recursos en línea, el término alfabetización ha tomado otra dimensión, al pasar de la habilidad de leer y escribir a otras más complejas para desenvolverse en una sociedad digitalizada, promoviendo el desarrollo económico, social y cultural de las naciones. Si a esto se une que la información podría entenderse como "(...) el conjunto de datos organizados y contextualizados; que se transmiten en el proceso de comunicación social; y que una vez asimilados permiten la solución de problemas, la toma de decisiones, la disminución de incertidumbre" (Pozo-Jara, 2017), podríamos referir de forma literal que alfabetización informacional se relaciona con las habilidades básicas para acceder a la información en diferentes formatos y con utilidad práctica para las personas. No obstante, como es de esperar esta definición es muy limitada para el ámbito económico, sociocultural y educativo actual como se verá a continuación.

Una de las definiciones más sencillas para este concepto la aportó la American Library Association (ALA) en 1989, al plantear que una persona alfabetizada informacionalmente "(...) debe ser capaz de reconocer cuándo necesita información y tener la capacidad de localizarla, 
evaluarla y usarla eficazmente" (Citado por: Sturges \& Gastinger, 2012). Asimismo, la Declaración de Alejandría del año 2005, en el marco del coloquio sobre el tema entre el National Forum on Information Literacy y la UNESCO, se concluye que la alfabetización informacional es vital para desarrollar un aprendizaje a lo largo de la vida, y que además de lo planteado por ALA, las personas deben ser capaces también de "crear información eficazmente para conseguir sus metas personales, sociales, ocupacionales y educativas" (Citado por: Pinto \& Uribe-Tirado, 2017).

Otras organizaciones como el Chartered Institute of Library and In-formation Professionals (CILIP) en 2004 mantienen la base de los conceptos anteriores. Sin embargo, sostienen que también se debe saber "cuándo y por qué se necesita información, dónde encontrarla, y cómo evaluarla, utilizarla y comunicarla de manera ética" (citada por Vidal Ledo et al., 2016). Esta misma organización para el año 2018 añade que el término es mucho más amplio, involucrando la interpretación juiciosa de la información, integrando competencias, cualidades y habilidades de pensamiento y conciencia críticas, así como la forma en que se utiliza esta desde el ámbito no solo ético sino también político (Sales, 2020).

A lo anterior se suma que la alfabetización informacional no incluye solo a la información escrita que encontramos en la web, sino también a los medios impresos, el discurso hablado, imágenes, los audios, videos, entre otras formas. Por eso, no es un concepto independiente, sino que involucra o relaciona con otras alfabetizaciones como la alfabetización digital (digital literacy), la alfabetización académica (academic literacy) y la alfabetización mediática (media literacy), entre otros (Sales, 2020). Esto supone entonces un alto grado de competencias y habilidades para la gestión eficaz de la información como forma de conocimiento individual y colectivo.

En este caso, en la revisión del tema realizado por Slavova y Garov (2019) se resume que desde inicios del siglo XXI en países como Australia y Nueva Zelanda se crearon estándares o habilidades más enfocadas a lograr personas alfabetizadas informacionalmente. Estos estándares están dirigidas al diseño de políticas nacionales para la adquisición, comprensión e implementación de la alfabetización informacional por parte de los ciudadanos, incluyendo los siguientes puntos:

- Reconocer las necesidades y la extensión en la que la información es requerida.

- Acceder a la información de una forma eficiente.

- Evaluar críticamente la información encontrada y las fuentes de origen.

- Clasificar, almacenar, manipular, reformular la información recopilada o generada.

- Incorporar la información seleccionada en su conocimiento de base.

- Utilizar la información de forma efectiva para aprender, crear nuevo conocimiento, solucionar problemas, tomar decisiones.

- Comprender los aspectos económicos, legales, sociales, políticos y culturales del uso de la información.

- Acceder y utilizar la información de forma ética y legal.

- Utilizar la información y el conocimiento para participar con responsabilidad social y ciudadana.

- Experimentar la alfabetización informacional como parte del aprendizaje independiente y para toda la vida. 
Resumiendo, la alfabetización informacional se refiere a todas las habilidades y aptitudes que permiten a una persona gestionar de forma eficaz y ética sus necesidades de información, aún si esta se encuentra en diferentes formatos o necesita del uso de recursos tecnológicos para su localización y acceso. De esta forma, debe incorporar criterios para reconocer y evaluar crítica y conscientemente los requerimientos de información, así como diseñar las estrategias más eficientes para la búsqueda, localización, identificación, recuperación, interpretación y evaluación de las fuentes más confiables y adecuadas, las cuales se emplearán para dar un valor agregado en la solución de un problema individual o colectivo.

Lo anterior se encuentra de acuerdo con la actualización que realizara la Comisión Europea, sobre el Marco para las Competencias Digitales para los Ciudadanos (The Digital Competence Framework for Citizens-DigComp 2.1). En este consenso no solo se indica que la alfabetización informacional está estrechamente imbricada con las competencias digitales, sino además que para lograrla una persona debe: identificar la necesidad de información, navegar, buscar, filtrar datos, información y contenido digital; crear y actualizar estrategias personalizadas de búsqueda; evaluar crítica y comparativamente la fiabilidad de las fuentes; organizar, almacenar y recuperar la información, datos y contenidos en ambientes digitales (Carretero et al., 2017). Por lo que, desde esta perspectiva las competencias digitales incluyen en parte a la alfabetización informacional, haciendo la salvedad de que esta última no solo alude a la información digital, sino también a la impresa y verbal como se mencionó previamente.

Ampliando lo anterior, el término Competencia Digital es relativamente reciente, ubicándose los orígenes del mismo desde el año 2010 en Europa continental y posteriormente en otras regiones, como Latinoamérica y Estados Unidos. Para un acercamiento inicial a su significado, se podría empezar por las palabras que la conforman. En tal caso, la Real Academia Española (RAE) se refiere a la "competencia", como "Pericia, aptitud o idoneidad para hacer algo o intervenir en un asunto determinado." (RAE, 2014). Si a esto se agrega que "digital" podría referirse a la comunicación y la computación, el acceso a Internet u otras plataformas (CarrilloGarcía et al., 2018), entonces, podría definirse que una persona competente digitalmente es aquella que puede manejar las TIC. No obstante, las competencias digitales son mucho más que la simple experticia en el manejo de programas y equipos informáticos y de comunicación digital.

En este contexto, el concepto de competencia digital es multidimensional, en el que se engloba un conjunto de habilidades y actitudes interrelacionadas entre sí que abarcan aspectos técnicos, informacionales, creación de contenidos, mediáticos, comunicativos, solución de problemas, así como la toma de decisiones estratégicas y éticas. Con lo anterior se puede ver que este término engloba más que simples habilidades tecnológicas, ya que también se enfoca a adquirir una posición crítica y segura respecto al uso de las TIC en la vida estudiantil, profesional, ocio, entre otras (Cabero-Almenara \& Palacios-Rodríguez, 2020; Sánchez-Caballé et al., 2020; Spante et al., 2018). Con esto coincide Lucas (2019) quien además refiere que estas habilidades y actitudes, de forma similar a las requeridas para una alfabetización informacional, son esenciales para la inclusión social, la participación cívica activa y consciente, y para un crecimiento inteligente, competitivo y sustentable de la sociedad actual. Por ello podría decirse que las competencias digitales se refieren a un concepto en constante renovación y mejora, debiendo adaptarse y evolucionar a la par que progresan las TIC, lo que ayuda además al desarrollo sociocultural y económico de la humanidad. 
Debido a la naturaleza siempre cambiante de las tecnologías en la actualidad, es difícil definir cuáles son las competencias básicas que se deben fomentar en los ciudadanos, ya que las mismas pueden cambiar en cortos periodos de tiempo. Por ello, algunas organizaciones actualizan cada vez de forma más frecuente sus marcos de competencias digitales. En este caso, a nivel de Europa, se ha actualizado en varias ocasiones el Marco de Competencias Digitales para los Ciudadanos (The Digital Competence Framework for Citizens-DigComp) el mismo que se ha ampliado a otras áreas más específicas como la educativa (DigCompEdu), organizaciones (DigCompOrg) y consumidores (DigCompConsumers). En su versión más reciente (DigComp. 2.1), destaca cinco áreas competenciales y 21 competencias digitales generales para la sociedad. Estas áreas son: 1. Alfabetización informacional y en datos (Information and data literacy); 2. Comunicación y colaboración (Communication and collaboration); 3. Creación de contenido digital (Digital content creation); 4. Seguridad (Safety); 5. Solución de problemas (Problem solving). Asimismo, las competencias involucradas con cada una de estas áreas, se resumen en la Tabla 1. (Carretero et al., 2017)

Tabla 1. Áreas y competencias digitales según DigComp 2.1.

\begin{tabular}{ll}
\hline Área & Competencias \\
\hline Alfabetización & - Navegar, buscar, filtrar datos, información y contenido \\
informacional y de datos & digital. \\
& - Evaluar datos, información y contenido digital. \\
Comunicación y & - Gestionar datos, información y contenido digital. \\
colaboración & - Interactuar con otros a través de las tecnologías digitales. \\
& - Compartir a través de las tecnologías digitales. \\
& - Involucrarse en la sociedad a través de las tecnologías \\
& digitales. \\
& - Colaborar a través de las tecnologías digitales. \\
& - Etiqueta digital (Netiquette) \\
Creación de contenido & - Gestión de la identidad digital. \\
digital & - Desarrollo de contenido digital. \\
& - Integrar y reelaborar contenido digital. \\
Seguridad & - Derecho de autor y licencias. \\
& - Programación. \\
& - Protección de dispositivos. \\
& - Protección de datos personales y la privacidad. \\
Solución de problemas & - Proteger la salud y el bienestar. \\
& - Proteger el medio ambiente. \\
& - Solucionar problemas técnicos. \\
& - Identificar necesidades y respuestas tecnológicas \\
& - Usar las tecnologías de forma creativa. \\
& - Identificar brechas en las competencias digitales. \\
\end{tabular}

Fuente: (Carretero et al., 2017)

Por otro lado, el Marco de Competencias Digitales adoptado por el Québec's Ministère de l'Éducation et de l'Enseignement Supérieur, Canadá, también tiene como visión una integración y uso óptimo de las tecnologías digitales para impulsar el éxito de los ciudadanos a través de habilidades que promuevan su desarrollo y mantenimiento del aprendizaje para toda la vida. De esta forma, definen más concretamente a las competencias digitales como las habilidades que se requieren para un uso creativo, crítico y apropiado de las tecnologías digitales en áreas diversas 
como el aprendizaje, el trabajo, esparcimiento, e inclusión o participación en la sociedad. Se añade además que una persona competente digitalmente puede adaptarse a las innovaciones tecnológicas, evaluar críticamente estas tecnologías y adoptar e implementar aquellas que resulten útiles en lo personal y social, para lo que se proponen 12 dimensiones claves que se resumen en la Figura 1. (Karsenti et al., 2020)

Figura 1. Dimensiones de las competencias digitales del Québec's Ministère de l'Éducation et de l'Enseignement Supérieur.

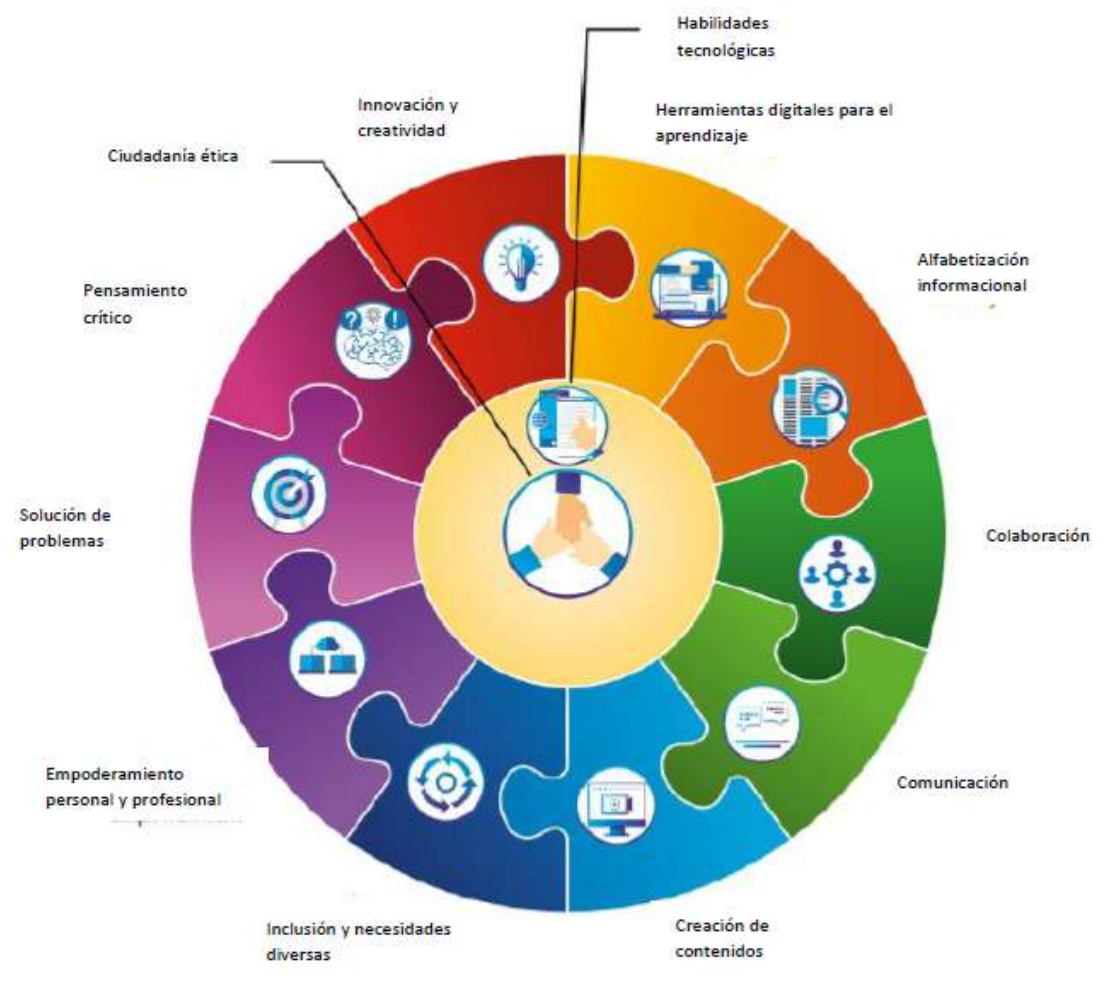

Fuente: Imagen adaptada de Karsenti et al., (2020)

Como puede apreciarse, existen múltiples conexiones entre las dimensiones propuestas por la Comisión Europea respecto a las que se desarrollaron en Canadá. No obstante, en el segundo planteamiento, se pone en el núcleo de todas las dimensiones, el desarrollo de una ciudadanía ética y competente tecnológicamente, en torno a las cuales giran todas las demás en una estrecha relación entre sí. De igual forma, la inclusión de las competencias informacionales, ayudan a comprender la importancia y relación de las competencias digitales con la alfabetización informacional.

Por último, el término Alfabetización Digital, es otro que tiende a mimetizarse en la literatura con los anteriormente planteados. Según Spante et al. (2018) este término se introduce a finales de la década de los años 90’s del siglo pasado por Gilster, quien lo definiría como la capacidad de comprender y utilizar la información en múltiples formatos de una amplia gama de fuentes cuando se presenta a través de computadoras. Como se observa, esta conceptualización se parece mucho a la de alfabetización informacional, tomando como base el hecho del uso efectivo de la información. 
Desde esas fechas y con el desarrollo de las TIC, el concepto de alfabetización digital también evolucionó, agregándosele tanto las habilidades cognitivas como competencias (Mishra et al., 2017). Así, la definición original queda modificada levemente por Chan et al. (2017) quien indica que esta se refiere a la "capacidad de entender y utilizar la información en múltiples formatos con énfasis en el pensamiento crítico más que en las habilidades de la comunicación y la información". A esto se añade el intento por diferenciar los conceptos de alfabetización informacional y alfabetización digital realizado por Machin-Mastromatteo (2012), quien resume que el primero se refiere a la capacidad del individuo para manejar la información en general, mientras que el segundo se enfoca más en el manejo de los dispositivos electrónicos (hardware y software). Este autor refiere que debería hablarse más en plural como alfabetizaciones (literacies) lo que comprendería tanto a la alfabetización digital como informacional.

Por su parte, Tang y Chaw (2016) emplean una definición más amplia, en la que se indica que la alfabetización digital se refiere al conocimiento, actitudes y capacidades de las personas para usar herramientas e instalaciones digitales. Este uso se realizaría con el fin de "identificar, acceder, gestionar, integrar, evaluar, analizar y sintetizar recursos digitales, construir nuevos conocimientos, crear expresiones mediáticas y comunicarse con otros”. Por eso se sostiene que este concepto en su desarrollo no privilegia la tecnología por sobre el conocimiento, sino que se ha enfocado mayormente a la adquisición de habilidades digitales, el desarrollo de modelos cognitivos digitales y la inclusión de culturas y prácticas digitales (Yépez-Reyes, 2018).

Todo lo anterior apoya los planteamientos de Spante et al. (2018) y de Coldwell-Neilson (2017) quienes indican la falta de precisión de las definiciones a estos conceptos. Esto se hace más notorio cuando se llevan al contexto educativo, específicamente a las habilidades y competencias de los docentes para enfrentar un proceso de enseñanza-aprendizaje de sus alumnos en un mundo efervescente de tecnologías de todo tipo y alcances. En el contexto latinoamericano se le debe sumar, además, la importante brecha digital a la que hacen frente no solo los docentes de diferentes instituciones y países, sino también los propios estudiantes, lo que limita de forma significativa el acceso a las TIC e internet, y por ende retrasa el desarrollo de personas alfabetizadas y competentes para una sociedad de la información y la comunicación.

Por eso el estudio de los conceptos tratados acá debe enfocarse según el contexto de las situaciones concretas de la vida de esa persona, en la que se posibilite una acción social constructiva y una reflexión sobre su proceso de adquisición de habilidades y competencia para una verdadera sociedad digital inclusiva. Con ello se puede resumir de una forma más directa aunque no exenta de sesgos: la alfabetización informacional se encarga de dotar a las personas de habilidades para la gestión eficiente, creativa y ética de la información; la alfabetización digital por su parte se enfoca hacia las habilidades para la gestión de las TIC para incluirse en esa sociedad de la información por lo que incluye a la primera y otros tipos de alfabetizaciones digitales; mientras que las competencias digitales, se enfocan más hacia la comprensión de las dimensiones globales de estas tecnologías y su potencialidad transformadora de la sociedad, incluyendo así, los diferentes tipos de alfabetizaciones digitales.

- La brecha digital antes de la "Era COVID 19” en Latinoamérica y las competencias digitales docente y estudiantil. 
El impacto de la COVID 19 en las esferas de Salud Pública y la Economía de los países es indiscutible y ha sido ampliamente difundida por diferentes medios a nivel mundial. Sin embargo, otra crisis muy importante y menos analizada es aquella que se desarrolla en el ámbito educativo, en la que esta pandemia se inserta como un factor que agrava más la significativa brecha digital y educacional ya existente (García Fernández et al., 2020; Lloyd, 2020; Rodicio-García et al., 2020).

En este sentido, las propuestas realizadas por la ONU (2020) y la CEPAL \& UNESCO (2020) para abordar esta emergencia se enfocan hacia una inversión para mejorar el acceso a recursos digitales y a fomentar prácticas educativas que tomen en cuenta fundamentalmente actividades en línea y a distancia. A esta propuesta se le podrían hacer dos observaciones importantes: ante la crisis económica actual y la que se avecina, es difícil lograr un compromiso de los gobiernos para realizar inversiones notables dirigidas a solucionar o al menos mitigar el problema de esta brecha digital que lleva años sin solucionarse; asimismo, una inversión que solo considere una alfabetización rápida y superficial, dirigida más a lograr habilidades técnicas básicas sin desarrollar competencias digitales tanto en docentes como en estudiantes y que además no contemple innovaciones pedagógicas o didácticas, podría ser de muy poco impacto. Aun así, la respuesta de muchas administraciones educativas fue trasladar las clases hacia la virtualidad, en ocasiones sin considerar el acceso del alumnado, docentes, familias e instituciones a las tecnologías de la información y las comunicaciones, ni tampoco la preparación pedagógica de los docentes para diseñar y planificar sus actividades significativas en un ambiente totalmente diferente al que estaban acostumbrados con sus alumnos.

Según Mendoza-Ruano y Caldera-Serrano (2014), el término brecha digital se refiere a un fenómeno complejo que debe verse como una nueva dimensión o extensión de las brechas sociales e históricas, asociadas a las relaciones de poder, y a otros factores como económicos, geográficos, educativos, de género y de edad, entre otros. De esta forma, este problema se manifiesta en forma de desigualdades entre las personas, comunidades o países respecto al acceso y uso de las TIC y de Internet. Este término también involucra el hecho del analfabetismo digital, referido a que, aunque tengan el acceso a estas tecnologías, no sepan utilizarle. En el contexto latinoamericano, este problema es muy notable en varios de sus países, como se verá a continuación.

En México, por ejemplo, antes de la pandemia una encuesta nacional indicaba que solo el $45 \%$ disponía de una computadora y solo el $53 \%$ tenía acceso a internet en casa. Estas diferencias eran más notables si se consideraba el área en la que vivía la persona, ya que si era urbana, el 73 $\%$ tenía acceso a internet $v s .40 \%$ en zonas rurales (INEGI, 2018). Por su parte en Ecuador, una encuesta nacional realizada justo antes de la crisis sanitaria mostró que solo el $40.6 \%$ de los hogares tenían al menos una computadora o Tablet, así como el $45.5 \%$ de tenían acceso a internet (56.1\% zonas urbanas vs. $21.6 \%$ en zonas rurales), con un $59.2 \%$ de personas que utilizan este servicio. A esto se suma que solo un $41 \%$ de las encuestados mayores de 5 años empleó una computadora en los últimos 12 meses antes de la pandemia, también con significativas diferencias por lugar de residencia. Asimismo, solo un $59.9 \%$ posee un teléfono activado, de los cuales el $76.8 \%$ es un Smartphone. Todo esto se une a un analfabetismo digital del $11.4 \%$ de la población general, la que llega a ser de $20.0 \%$ en zonas rurales (Equipo técnico Encuesta Nacional Multipropósito de Hogares, 2020). 
Un panorama diferente a los anteriores se observa en Chile y Argentina antes de la pandemia, países en los que más del $80 \%$ de los hogares declararaba tener acceso a internet, más del 90\% teléfonos móviles o Smartphone y cerca del $60 \%$ una computadora personal (INDEC, 2020; IX Encuesta de Acceso y Usos de Internet, 2017). Todos estos datos también contrastan con los observados en otros países como España, donde antes de la pandemia el $91.4 \%$ de los estudiantes tenía acceso a internet a través de su teléfono móvil y el $80.9 \%$ lo hacía a través de un ordenador personal. Estos valores se elevaron a $96,7 \%$ y a $83.6 \%$ respectivamente durante la pandemia (Rodicio-García et al., 2020).

Lo expuesto en cifras hasta el momento, podría entenderse como que la brecha digital solo se refiere al acceso a la tecnología, el internet y su manejo. Sin embargo, esta brecha también se manifiesta en el pobre desarrollo de las habilidades necesarias para incluir a las personas en una verdadera sociedad de la información y las tecnologías. De esta forma, el autor considera que podría observarse a personas "analfabetas digitales funcionales", puesto que no basta haber nacido en la era de la internet y saber manipular las TIC para algún beneficio personal, sino que se requiere además de habilidades para su manejo eficiente, inclusivo y transformador de la sociedad. Y es justamente aquí, donde los educadores juegan un papel crucial (Fernández-Cruz \& FernándezDíaz, 2016; Gisbert Cervera et al., 2016).

\section{- Competencias digitales docentes.}

Las competencias digitales docentes podrían definirse como el conjunto de conocimientos, habilidades y actitudes necesarios para utilizar las TIC como recursos educativos integrados en su práctica de la enseñanza y el aprendizaje (Cabero-Almenara \& Palacios-Rodríguez, 2020; Solís de Ovando Calderón \& Jara Jara, 2019). Esto conlleva además a un cambio pedagógico y didáctico de la práctica docente, donde el profesor, ante tan abrumadora cantidad de información, debe pasar de transmisor de conocimientos a facilitador del acceso, selección, evaluación y transformación del mismo por parte del estudiante. De esta forma, un maestro competente sería el que integre en su práctica educativa un conocimiento de triple enfoque: disciplinar, pedagógico y tecnológico. Así, no basta con conocimientos enciclopédicos, también debe ser capaz de diseñar las mejores estrategias didácticas y pedagógicas para alcanzar los objetivos de aprendizaje, incluyendo recursos tecnológicos que los faciliten y potencien (Gisbert Cervera et al., 2016).

Definir cuáles son las competencias digitales docentes tampoco es una tarea fácil, por lo que algunas organizaciones como la UNESCO se refieren a ello en múltiples ocasiones, desarrollando documentos y orientaciones para las instituciones educativas que aún no tienen muy claro el tema de lo que deben saber los profesores sobre el uso de las TIC en el mundo educativo actual. En este sentido se propone una mejora en la práctica educativa no solo elevando las habilidades digitales de los docentes, sino también combinándoles con innovaciones pedagógicas, organizativas y curriculares. De esta forma se apuesta también por una calidad de la enseñanza mediante el desarrollo de habilidades psicoeducativas, habilidades vocacionales y de liderazgo, así como habilidades colaborativas y cooperativas. Esto contribuiría a motivar en los estudiantes las llamadas habilidades del siglo XXI, que son el pensamiento crítico y creativo, la comunicación y la colaboración. A esto se une la propuesta de una práctica profesional docente en torno a seis aspectos importantes: 1. Comprensión del papel de las TIC en las políticas educativas, 2. Currículum y evaluación, 3. Pedagogía, 4. Aplicación de competencias digitales, 5. Organización 
y Administración, 6. Aprendizaje profesional de los docentes. Para ello, propone tres niveles sucesivos de desarrollo en cada uno de estos temas (Figura 2) (UNESCO, 2019).

Primer nivel: Adquisición de conocimientos; donde el docente se alfabetiza digitalmente, familiarizándose con competencias básicas en TIC y su uso en el ámbito educativo, dentro de políticas y prioridades nacionales. En este caso, se aplican las competencias logradas para potenciar una enseñanza empleando las TIC en un aula estándar.

Segundo nivel: Profundización de conocimientos; en este caso, el docente es capaz de aplicar las políticas y conocimientos alcanzados en competencias TIC para promover la solución de problemas complejos a través de grupos profesionales de colaboración y en redes. Todo esto centrado en el desarrollo integral de los educandos.

Tercer nivel: Creación de conocimientos; donde el docente se muestra con competencias de alto nivel que le permiten innovar para modelar y gestionar su propia práctica educativa, promoviendo una transformación política y social mediante el desarrollo curricular de competencias de la sociedad del conocimiento.

Figura 2. El Marco de las Competencias Docentes en materia de TIC.

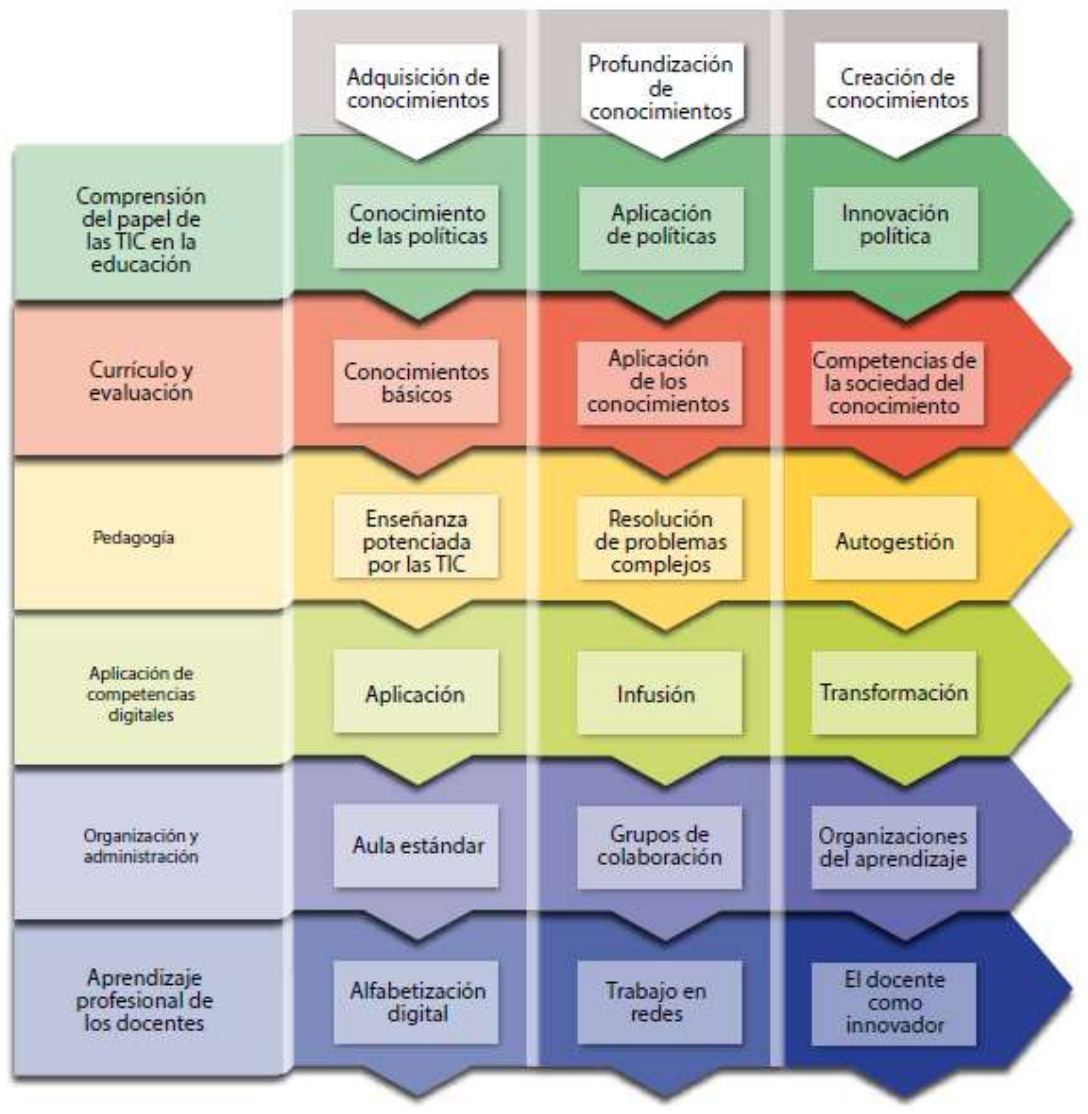

Fuente: (UNESCO, 2019)

Se debe indicar que, si bien los conceptos anteriores suponen una guía para la implementación de estrategias de desarrollo profesional de los docentes en competencias digitales, estos son muy generales y deben contextualizarse a las realidades nacionales o locales donde se 
desee implementar. En ello se deben integrar no solo las políticas educativas, sino también las inversiones en infraestructura y sistemas continuos de capacitación y mejoramiento de la calidad del ejercicio docente. Considerando lo anterior, han surgido otras alternativas a la propuesta de la UNESCO, siendo una de las más llamativas la de la Comisión Europea. En este caso, en 2017 se publica el Marco Europeo de Competencia Digital del Profesorado o también conocido como DigComEdu. En este caso se presentan de forma más específica 22 competencias digitales docentes organizadas en seis áreas estrechamente relacionadas, las que responden a las competencias profesionales y pedagógicas del docente y las que se enfocan a los educandos. Éstas áreas se resumen a continuación y se muestran en la Figura 3 (Cabero-Almenara \& PalaciosRodríguez, 2020; Caena \& Redecker, 2019):

1. Compromiso personal (Professional Engagement): en esta se engloban destrezas sobre el uso eficiente y apropiado de la tecnología, sacando provecho de las oportunidades que ofrecen la comunicación y colaboración con los colegas, padres y estudiantes, para un aprendizaje digital más efectivo. Además, enmarca la capacidad de los docentes para reflexionar individual, colectiva y críticamente sobre sus prácticas de enseñanza y sus estrategias digitales de enseñanza. Esto permitiría desarrollar mejoras continuas al proceso educativo.

2. Recursos digitales (Digital Resources): relacionada con cómo el docente puede seleccionar, crear, modificar y distribuir recursos digitales para su práctica educativa. Esto también incluye el manejo seguro y la protección de datos personales, así como el respeto a las normas de derecho de autor.

3. Pedagogía digital (Teaching and Learning): considera las diferentes etapas del proceso enseñanza-aprendizaje para diseñar, planificar e implementar las tecnologías digitales con un objetivo educativo. Promueve el uso de las TIC en procesos colaborativos y autorregulados de aprendizaje, acompañando este proceso con una guía adecuada y medidas de apoyo.

4. Evaluación y retroalimentación (Assessment): se enfoca en el cómo emplear las herramientas, recursos y estrategias digitales para la evaluación, seguimiento y retroalimentación oportuda del desempeño estudiantil, así como para la mejora del proceso de enseñanza-aprendizaje, así como nuevos y mejores métodos de evaluación.

5. Empoderar a los estudiantes (Empowering Learners): impulsar mediante la tecnología digital, la autonomía estudiantil y la participación activa de los estudiantes en su propio proceso de aprendizaje. De esta forma las TIC pueden favorecer procesos de enseñanza personalizada y diferenciada, respetando los diferentes niveles, ritmos e intereses de los educandos.

6. Facilitar la competencia digital de los estudiantes (Facilitating Learners' Digital Competence): se direcciona a cómo los docentes pueden favorecer las competencias digitales de sus estudiantes, capacitándoles para que puedan tomar riesgos y utilizar las TIC de forma segura y responsable. En este sentido, los docentes deben ser capaces de diseñar e implementar actividades integrales que promuevan la alfabetización mediática e informacional, para que puedan solucionar problemas digitales, crear contenidos digitales y empleen estas tecnologías para la comunicación y la cooperación. 
Figura 3. Áreas y competencias docentes y sus relaciones según DigCompEdu.

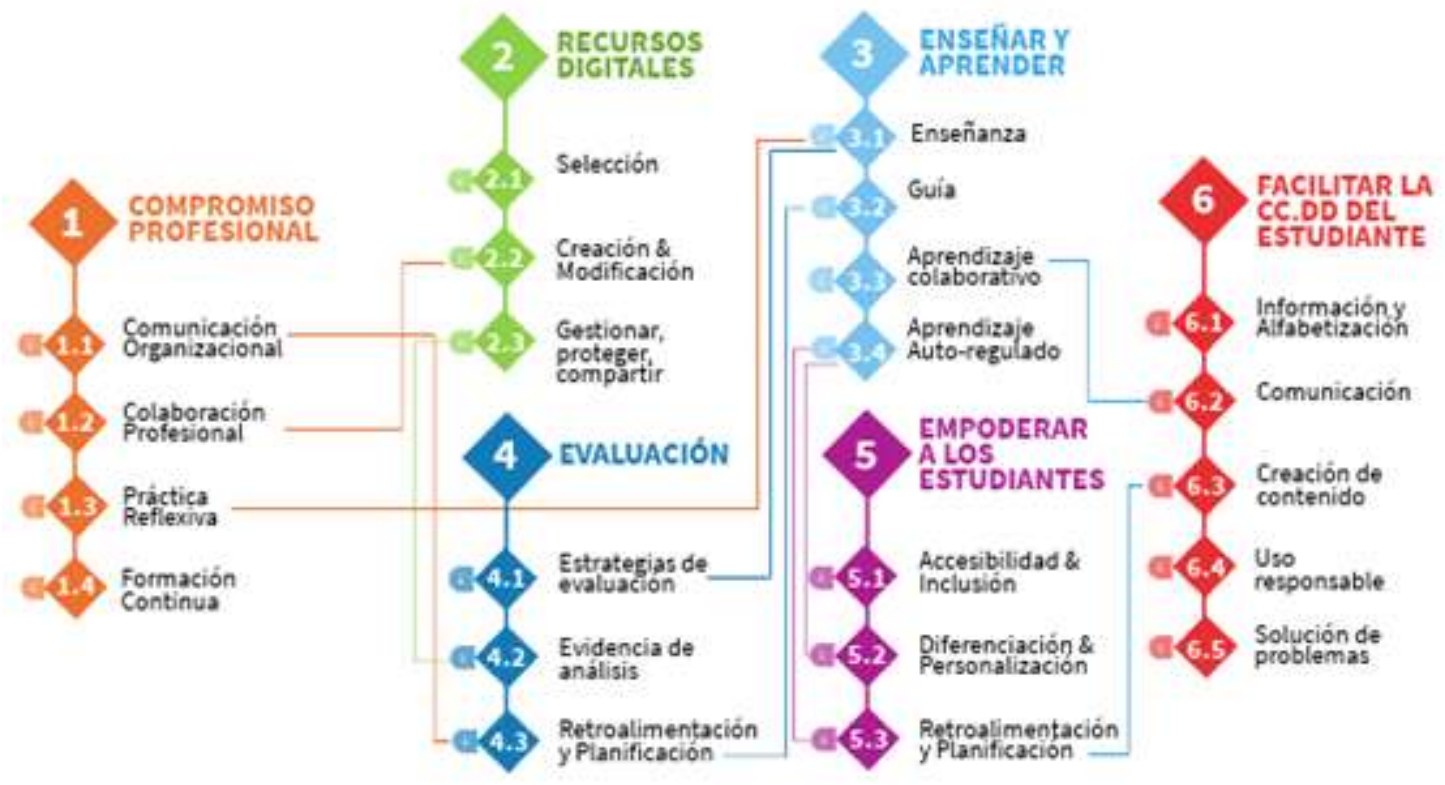

Fuente: Adaptado de, Caena \& Redecker (2019)

Según lo descrito, el área 1, es el núcleo profesional de este marco, relacionado con las competencias que todo docente, comprometido con una Sociedad del Conocimiento, debe alcanzar para mejorar su práctica educativa. Las áreas 2, 3, 4 y 5, se constituyen con el núcleo pedagógico, ya que se relacionan directamente con el proceso de enseñanza-aprendizaje. Por último, el área 6 se relaciona con los ciudadanos y ciudadanas que se desea formar para enfrentar en el futuro la evolución tecnológica (Cabero-Almenara \& Palacios-Rodríguez, 2020; Caena \& Redecker, 2019).

Todas estas áreas se evalúan según seis niveles de competencia: el nivel A1 (Novato) y A2 (Explorador) donde se agrupan los docentes que se inician en el uso de la tecnología para mejorar sus prácticas profesionales y pedagógicas; B1 (Integrador) y B2 (Experto) ya integran la tecnología en una variedad de formas y contextos; C1 (Líder) y C2 (Pionero o innovador), ellos comparten su experiencia con sus colegas, así como experimentan con tecnologías innovadoras complejas y desarrollan nuevos métodos pedagógicos, enfoques y estrategias de evaluación (Caena \& Redecker, 2019). La evaluación del nivel de competencias digitales se evalúa así con una herramienta digital denominada DigCompEdu Check-in, de la que existe una versión en español (Cabero-Almenara \& Palacios-Rodríguez, 2020) que puede experimentarse de forma gratuita en el siguiente sitio: https://ec.europa.eu/eusurvey/runner/DigCompEdu-H-ES?language=es .

Al observar las propuestas de la UNESCO y de la Comisión Europea se puede notar que ambas persiguen aspectos similares. Primero, el desarrollo del docente como profesional donde se pretende elevar sus competencias TIC para aplicarlas en su labor diaria. Segundo, el desarrollo del docente desde el ámbito pedagógico, buscando estrategias que fomenten una buena práctica diaria mediante la inclusión de las TIC, para mejorar el aprendizaje de sus estudiantes y de sí mismo, a través de la colaboración y la cooperación. Tercero, el desarrollo integral de los educandos para una sociedad del conocimiento digital como resultado de las anteriores. 
Además de estos, otro de los modelos aplicados en el ámbito latinoamericano tanto para docentes como para estudiantes es el del International Society for Technology in Education (ISTE) para docentes en EEUU, con sus Estándares de Tecnologías de la Información y la Comunicación (NETS-T). En este se presentan cinco dimensiones relativamente prácticas y aplicables a cualquier contexto: Aprendizaje y creatividad de los alumnos; Experiencias de aprendizaje y evaluaciones propias de la era digital; Trabajo y aprendizaje característicos de la era digital; Ciudadanía digital y responsabilidad; Crecimiento profesional y liderazgo. En este caso se dispone de múltiples estándares y rúbricas para dar una clasificación en cuatro niveles: principiante, medio, experto y transformador. Estos estándares para diferentes áreas se pueden consultar en la página del ISTE en la siguiente dirección: https://cutt.ly/zhT37AL. Se trata de un modelo cercano a las teorías constructivistas del aprendizaje y que considera a las TIC y la educación de una forma más holística y transdisciplinar (Esteve-Mon et al., 2016).

Ya en el contexto latinoamericano específicamente, se encuentran los aportes de Rangel Baca (2015) quien basándose en la revisión de la literatura y el juicio de expertos, propone un perfil de competencias digitales práctico y cercano a la realidad de los docentes de la región, constituido por tres dimensiones: tecnológica, informacional y pedagógica. Estas dimensiones abarcan 13 competencias docentes y 52 indicadores de logro. Según esta propuesta, las competencias propuestas por cada dimensión se resumen en la tabla 2. De esta se debe decir que se centra mayormente en el docente, mas no en el estudiante, el que se supone quede beneficiado de la misma en su proceso de aprendizaje.

Tabla 2. Dimensiones y competencias digitales para el docente latinoamericano.

\begin{tabular}{|c|c|c|}
\hline Dimensión & Definición & Competencias digitales docentes \\
\hline Tecnológica & $\begin{array}{l}\text { Se enfoca en los conocimientos } \\
\text { básicos sobre el funcionamiento y } \\
\text { el uso de las TIC en el ámbito } \\
\text { profesional, lo que incluye el } \\
\text { manejo de programas informáticos } \\
\text { básicos, la seguridad informática } \\
\text { básica y el mantenimiento de los } \\
\text { equipos informáticos. De igual } \\
\text { modo, explora la disposición de los } \\
\text { docentes a mantenerse actualizados } \\
\text { en este tema. }\end{array}$ & $\begin{array}{l}\text { C1. Maneja conceptos y funciones } \\
\text { básicas de la computadora. } \\
\text { C2. Realiza tareas básicas de } \\
\text { conectividad, instalación y seguridad } \\
\text { del equipo de cómputo. } \\
\text { C.3. Maneja funciones básicas de los } \\
\text { programas de productividad. } \\
\text { C.4. Muestra una actitud positiva } \\
\text { para su actualización permanente en } \\
\text { temas relacionados con las TIC. }\end{array}$ \\
\hline \multirow[t]{4}{*}{ Informacional } & $\begin{array}{l}\text { Conocimientos y habilidades } \\
\text { necesarios para gestionar mediante }\end{array}$ & $\begin{array}{l}\text { C.5. Sabe cómo localizar y recuperar } \\
\text { información. }\end{array}$ \\
\hline & $\begin{array}{l}\text { las TIC la información que se } \\
\text { recupera de Internet, de una forma }\end{array}$ & $\begin{array}{l}\text { C.6. Analiza y selecciona la } \\
\text { información de manera eficiente. }\end{array}$ \\
\hline & & $\begin{array}{l}\text { C.7. Organiza la información } \\
\text { recuperada de Internet de manera } \\
\text { adecuada. }\end{array}$ \\
\hline & & $\begin{array}{l}\text { C.8. Utiliza y presenta la } \\
\text { información de manera eficaz, ética } \\
\text { y legal }\end{array}$ \\
\hline Pedagógica & $\begin{array}{l}\text { Abarca el nivel de conocimiento } \\
\text { sobre cómo las TIC impactan y } \\
\text { posibilitan la educación, a través de } \\
\text { su integración en la planeación, el }\end{array}$ & $\begin{array}{l}\text { C.9. Muestra una actitud crítica y } \\
\text { favorable ante la posibilidad de } \\
\text { integrar las TIC en su práctica } \\
\text { docente. }\end{array}$ \\
\hline
\end{tabular}


desarrollo y la evaluación de la práctica docente en el proceso de enseñanza-aprendizaje.

C.10. Diseña e implementa
estrategias de enseñanza y
aprendizaje mediadas por TIC.
C.11. Diseña y evalúa materiales o
recursos educativos en soporte
digital, para integrarlos en su
práctica docente.
C.12. Emplea las TIC para apoyar las
tareas administrativo-docentes.
C.13. Emplea las TIC para
intercambiar ideas, información,
experiencias o conocimientos con
alumnos, colegas o expertos.

Fuente: (Rangel Baca, 2015)

A pesar de lo anterior, muchos trabajos indican falencias en las competencias digitales que poseen los docentes para enfrentar el escenario actual de la educación. En tal sentido, un estudio realizado en Portugal con docentes de Bachillerato, sostiene que su nivel de competencia digital es moderado, con los valores más bajos en las competencias pedagógicas y el fomento de las competencias de los estudiantes. Específicamente señala las subdimensiones de evaluación, empoderamiento de los estudiantes y la de facilitar la competencia digital de los alumnos, fueron las de menor puntaje (Dias-Trindade et al., 2020).

Esto es apoyado por el trabajo de Fernández-Cruz \& Fernández-Díaz, (2016) en más de mil docentes de 80 colegios de la Comunidad de Madrid. En este sentido, sus resultados muestran una diferencia alarmante entre las competencias digitales que poseen los docentes con las que deberían tener para fomentar las mismas en sus estudiantes. Se observa así que un 46,31\% de los profesores posee un perfil malo o muy malo respecto a su formación en TIC, lo que puede depender desde la edad, hasta el sexo, la experiencia profesional, la titulación obtenida, las asignaturas impartidas, los recursos TIC en casa, la actitud, entre otras. Esto queda además confirmado por otros autores como Hinojo Lucena et al. (2019) en Andalucía y por Falcó Boudet (2017) en la Comunidad Autónoma de Aragón, quienes concuerdan que los docentes poseen un nivel bajo en competencias relacionadas con el aprovechamiento didáctico de las TIC, relacionado también con la edad, el tipo de centro, entrenamientos previos en TIC, el grado académico, la experiencia, entre otros.

Considerando estos antecedentes, las investigaciones también se han enfocado en estudiantes de carreras universitarias de formación de Educadores. En este sentido, el trabajo de Casillas et al. (2017) en estudiantes en formación para Maestros, muestra puntajes en competencias digitales como conocimiento, uso y actitudes hacia las TIC, en valores medios, siendo mayores en los hombres que en las mujeres.

En el ámbito latinoamericano, la información revela que en Chile, los estudiantes de Pedagogía refieren que durante su carrera las competencias digitales han estado "marcadas por la utilización de aplicaciones tradicionales como Word, Excel o Power Point, no ocurriendo lo mismo con otro tipo de software" (Flores-Lueg \& Roig Vila, 2016). También en estudiantes de Pedagogía de Chile y Uruguay, se observó un nivel de competencias docentes básicas en las cuatro 
dimensiones analizadas: Curricular, didáctica y metodológica; Planificación, organización, gestión de espacios y recursos tecnológicos digitales; Aspectos éticos, legales y de seguridad; Desarrollo personal y profesional (Silva et al., 2019). Por su parte, en Ecuador, los resultados muestran que los docentes de Matemáticas nivel medio "tienen opiniones negativas acerca del impacto que tiene la competencia digital en el proceso de enseñanza-aprendizaje de la matemática, (...), por falta de conocimiento y dominio para aplicarlas en la docencia" (Revelo-Rosero et al., 2019).

En este mismo sentido, un trabajo sobre el tema que compara países como Costa Rica y España en maestros de Educación Primaria revela que los docentes tienen dificultades en competencias tales como la organización y análisis de la información para determinar su finalidad y relevancia (Área Información), la colaboración digital para crear recursos, contenidos y conocimientos (Área Comunicación), el uso adecuado de los derechos de la propiedad intelectual y las licencias de uso en internet (Área Creación), y la solución de problemas técnicos y de softwares en general. Esto influye en que los estudiantes se perciban con un nivel bajo de competencias digitales en todas las áreas evaluadas (Pérez-Escoda et al., 2020).

Todo lo anterior sugiere la necesidad de elevar las competencias digitales de los docentes para enfrentar los nuevos retos de la educación desde el desarrollo profesional que integre nuevas metodologías y pedagogías innovadoras que incluyan las TIC como parte transversal de los currículums a todos los niveles educativos.

\section{- Competencia digital estudiantil.}

En el campo educativo, social y tecnológico según González Calatayud et al. (2018) se distinguen múltiples términos para identificar a las personas según su relación temporal con las TIC. De esta forma se observan conceptos como "nativos digitales" e "inmigrantes digitales" para diferenciar a los que habían nacido con las tecnologías de los que no, los que debieron adaptarse a la misma y aprenderlas de adultos. Así también se distinguen otros conceptos más sonantes como Baby Boomers, la Generación X, Y o Z y Generación Net. Lo anterior podría generar la falsa expectativa de que los que nacieron con las tecnologías más competentes para el trabajo con las TIC.

Enfocándose específicamente al área de la Educación, se podría definir como competencias digitales estudiantiles, aquellas que debe desarrollar y utilizar un educando para un aprendizaje efectivo y a lo largo de la vida, de forma autónoma, crítica, reflexiva, ética, en cooperación y colaboración con los demás, empleando para ello las TIC y la Internet de una forma segura y creativa (Cabezas González et al., 2017). Esto se encuentra en la propuesta de la Comisión Europea del Marco de Competencias Digitales para los Ciudadanos mencionada anteriormente, considerando las cinco áreas competenciales: Alfabetización Informacional y de Datos, Comunicación y Colaboración, Creación de Contenido Digital, Seguridad y Solución de Problemas.

Una parte significativa de las investigaciones sobre competencias digitales en estudiantes proceden de instituciones españolas. En este caso, un trabajo realizado sobre en unos 350 estudiantes universitarios indica que los estudiantes muestran mayores competencias en el uso del ordenador y de la instalación-desinstalación de programas, así como con los conocimientos requeridos para acceder, buscar y recuperar información en diferentes formatos, con bastante 
homogeneidad entre los participantes. Por otra parte, las puntuaciones más bajas se refieren a automatización de procesos y conocimientos sobre compatibilidad entre hardware y software. De igual forma, la mayoría considera que no puede solucionar problemas que se presentan con el internet o con la computadora. Asimismo, existe una gran heterogeneidad para el empleo de opciones de búsqueda avanzada y en otras habilidades relacionadas con el paso de archivos entre computadoras, la colaboración en internet, la creación o modificación de contenidos audiovisuales, entre otros (Prendes-Espinosa et al., 2010).

Con los resultados anteriores concuerdan estudios más recientes como el de RodicioGarcía et al., (2020), quienes sustentan que la mayoría de los estudiantes universitarios españoles refieren no tener las habilidades tecnológicas adecuadas para su desempeño, así como dificultades para implementar su estudio y ponerse al día con los cambios constantes de las TIC. También resaltan los resultados de Pascual et al. (2019) en estudiantes universitarios del Grado de Maestro en Educación primaria, en los que se nota un desconocimiento de la gestión de la información, en la comunicación, el seguimiento de la huella digital, así como en las carencias sobre cómo resolver nuevos problemas informáticos. Asimismo, los datos de tres universidades europeas muestran con más que la mayoría de los más de 1000 estudiantes próximos a graduarse, tienen competencias intermedio-altas en alfabetización digital e informacional, mientras que en la creación de contenidos, especialmente en la creación de contenido multimedia y su diseminación es intermedia-baja (López-Meneses et al., 2020).

En el caso de los estudiantes de escuela secundaria o primaria, las investigaciones son más escasas. En este sentido, un trabajo realizado en Italia, sobre una muestra de más de mil adolescentes de nivel secundario de enseñanza (14-16 años), mostró que la hipótesis de que las competencias digitales están bien desarrolladas en esta generación, no es del todo correcta. Se observó así altas competencias en los aspectos técnicos, mucho más que en las dimensiones de la conciencia crítica y la socio-emocional. Llama la atención que apenas un $65 \%$ puede realizar una búsqueda adecuada en internet, mientras que solo un $50 \%$ puede evaluar la confiabilidad de la misma y otro $43 \%$ puede delimitar su búsqueda (Calvani et al., 2012).

Por otro lado, en Bulgaria, a pesar de que se tiene un sistema educativo encaminado a desarrollar competencias digitales en sus estudiantes de nivel secundario, más del $80 \%$ de ellos obtuvieron puntajes medios a bajos en las competencias básicas relacionadas con el Marco Europeo de Referencia de Competencias Digitales en las áreas de información, comunicación, creación de contenidos, seguridad y solución de problemas (Slavova \& Garov, 2019). Asimismo, la pesquisa de Pérez-Rodríguez et al. (2019) en 10 provincias de España con 672 estudiantes de estos niveles, muestran que la mayoría presenta solo niveles medios de competencia mediática, y aproximadamente, solo un $10 \%$ se encuentra en el nivel avanzado. Los peores niveles se encuentran en dimensiones relacionadas con procesos de programación y producción, así como en ideología y valores, donde el $70 \%$ o más se encuentra en un grado básico.

En el ámbito latinoamericano, los resultados en el diagnóstico de este tema son heterogéneos, lo que depende de la diversidad de metodologías, objetivos, población, instrumentos empleados y alcances. Esto queda registrado en la revisión realizada por Henriquez-Coronel et al. (2018) en la que se sostiene la hipótesis de que no hay evidencias para argumentar que los estudiantes poseen competencias digitales de alto nivel: en algunos países como en Chile el 
aproximadamente el $50 \%$ de los jóvenes presentan bajas competencias digitales, mientras que en otros como Costa Rica y México, la mayoría de ellos se poseen un nivel medio. Todo esto concuerda con la necesidad desarrollar estrategias curriculares para elevar las habilidades y competencias de los estudiantes en el manejo seguro, eficiente, responsable y crítico de las nuevas tecnologías digitales (Pérez-Escoda et al., 2020; Sánchez-Caballé et al., 2020).

Se puede mencionar acá también el trabajo de Crawford-Visbal et al. (2020) con estudiantes de la carrera de Comunicación de cuatro universidades latinoamericanas (Argentina, Colombia, Perú y Venezuela), en el que se aplicaron diferentes técnicas para recoger los datos: grupos focales, entrevistas semiestructuradas y cuestionarios. Se evaluaron tres de las áreas competenciales dadas en el Marco de la Comisión Europea para la Competencia Digital: Comunicación y colaboración; Creación de contenido digital; Búsqueda de información en internet. En este último, muy pocos estudiantes realizan sus búsquedas en bases de datos o en sitios web académicos, la mayoría realiza una simple búsqueda en Google. La mayoría comparten contenido online, pero muy pocos crean videos o audios-podcast y muchos menos multimedia. Si bien más del $50 \%$ crea contenidos digitales, la frecuencia con la que lo comparten es ocasional.

Otra pesquisa similar fue la realizada por Martínez Navarro (2020) en estudiantes de 15 universidades de cinco países latinoamericanos (Chile, Colombia, Ecuador, Perú y Venezuela). En tal caso, se evaluaron cuatro competencias digitales: Alfabetización informacional, Alfabetización tecnológica, Alfabetización multimedia y Alfabetización comunicativa. Los resultados muestran que, tanto en hombres como en mujeres, las competencias relacionadas con la alfabetización informacional fueron las mejor puntuadas, seguidas de las mediáticas, la tecnológica y por último las comunicativas, presentándose a Chile y Colombia como los mejor ubicados, y Ecuador el peor. Esto está en concordancia con el hecho de que la mayoría de los estudiantes de este país localizan información en fuentes no confiables como simples búsquedas en Google, Yahoo o Wikipedia, respecto a aquellos que emplean bases de datos con información especializada como el Google Académico, Scopus, Web of Science, entre otros (Sánchez Marrero et al., 2019). Asimismo, si bien la mayoría declara saber cómo navegar en internet y localizar información por diferentes buscadores, para otras habilidades como emplear herramientas de organización del tiempo, trabajo colaborativo y creación de contenidos los puntajes son mucho menores (Vázquez-Cano et al., 2017).

Por todo lo anterior es que se plantea la hipótesis de que, aunque los estudiantes puedan haber nacido y crecido en un mundo digital, no necesariamente tienen las competencias digitales adecuadas para enfrentar con eficiencia los estudios y su desarrollo personal. Por ello, se requieren de estrategias para fomentar estas competencias en los futuros ciudadanos para que no solo comprendan la tecnología y su impacto sociocultural y económico, sino para que sean capaces de utilizar las mismas en pos de mejorar esas sociedades y aprender durante toda su vida.

\section{- ¿Cómo fomentar las competencias digitales en los estudiantes en el contexto actual?}

La necesidad de elevar las competencias digitales tanto en docentes como en estudiantes es una realidad, más aún en el contexto actual, en el que una pandemia viral acrecienta aún más la brecha digital y profundiza la crisis de los sistemas educativos actuales. Por ello, algunas iniciativas se han venido desarrollando en los últimos años para fomentar estas competencias desde el papel innovador de las instituciones educativas, partiendo del hecho de que un docente 
competente en el ámbito digital, también podría fomentar esas competencias en sus estudiantes. Por eso, las estrategias se enfocan tanto a nivel macro como microcurricular, siendo algunas de las más populares las acciones institucionales para desarrollar e implementar planes, cursos, cambios curriculares y otros programas, fundamentalmente a nivel universitario. De esta forma se ha visto que los estudiantes prefieren adquirir estas habilidades mientras son guiados en sus asignaturas, y esperan que las instituciones y profesores les apoyen durante este proceso de aprendizaje (Sánchez-Caballé et al., 2020).

Para este tema se han desarrollado previamente, experimentos y estrategias de diversa índole, promoviendo el uso de metodologías activas para conseguir sus objetivos. En el caso de los primeros, se debe señalar el trabajo de Slavova y Garov (2019) en estudiantes de secundaria en Bulgaria. Estos autores diseñaron una intervención sencilla con diferentes metodologías cuya traducción se resume a continuación:

1. Asignar una tarea para refrescar sus conocimientos en:

1.1. Búsqueda y análisis de información de internet en un tema relacionado con las tecnologías de la información. Verificar la autenticidad de las fuentes y sistematizar la información encontrada.

1.2. Darle formato al texto en un documento, siguiendo determinadas reglas para ello.

1.3. Trabajar con hojas de cálculo en la solución de problemas prácticos relacionados con sus asignaturas. Además, deben analizar la información que se les da, desarrollar cálculos de acuerdo a la tarea y resumir los resultados en diagramas o gráficos.

1.4. Crear presentaciones de un tópico determinado relacionado con los temas de su currículum.

1.5. Trabajar con documentos en formato PDF, crear éstos usando programas de procesamiento de textos, hojas de cálculo y presentaciones.

Durante este proceso, los estudiantes autoevalúan sus tareas por criterios definidos por el docente, también realizan una coevaluación de los trabajos de sus compañeros y después entregan los mismos al docente mediante la nube. Así desarrollan el pensamiento lógico y crítico. Cada tarea práctica irá incrementando en dificultad para promover y fortalecer sus competencias.

2. Los estudiantes participan en pruebas online creadas por el docente para verificar sus avances. En ellos se incluyen tópicos de ciencias de la computación, así como sobre tecnologías de la información, solucionando estos test mediante sus teléfonos celulares.

3. En una última fase, los estudiantes trabajan en proyectos en el campo de las tecnologías de la información. Trabajan colaborativamente en documentos compartidos.

Los resultados obtenidos por los investigadores al pasar de un año lectivo (2016/2017) a otro (2017/2018) son prometedores: el desempeño en competencias digitales se eleva en más del $50 \%$ refiriéndose a los puntajes que superan los límites para otorgar una certificación. Algo similar ocurre con la tarea colaborativa indicada en la última fase del proceso.

Similar a este trabajo se encuentran las estrategias didácticas dirigidas a un Aprendizaje Basado en Proyectos (ABP). Este enfoque organiza el aprendizaje estudiantil en torno de la 
solución de problemáticas del mundo real, a través del planteamiento de un proyecto que el estudiante debe desarrollar, ejecutar, analizar y presentar resultados. De esta forma favorece el aprendizaje de forma integrada y dinámica (Botella Nicolás \& Ramos Ramos, 2019). Así, una experiencia en la materia de formación en TIC del Grado de Maestro en Educación Infantil de la Universidad de Santiago de Compostela, resume los resultados de un trabajo donde se le pide a los estudiantes que diseñen de un proyecto didáctico con TIC para un centro y alumnado de 5-6 años. En el desarrollo del mismo se enfatiza en competencias informacionales, creación de contenidos, seguridad, entre otras dimensiones de las competencias digitales. De esta forma se obtuvieron resultado elevados en la satisfacción de los estudiantes respecto a su formación en competencias relacionadas con los componentes didáctico-pedagógico y de desarrollo profesional. En una dinámica similar, Albertos et al. (2016) obtienen también resultados positivos en estudiantes de Ingeniería, con una estrategia de investigación-acción; mientras que González Calatayud et al (2018) logran resultados positivos en estudiantes de Pedagogía mediante tareas dirigidas.

Estas propuestas demuestran que se pueden insertar el desarrollo de competencias digitales estudiantiles de una forma transdisciplinar, con tareas que no se concentren solo en las habilidades del manejo de las herramientas TIC, sino también en cómo se puede evaluar el producto obtenido con el uso eficiente de las mismas.

Otra de las estrategias propuestas ha sido la "saturación tecnológica" de los centros educativos, promoviendo el modelo OLPC (One Laptop Per Child) o 1:1 con la finalidad de implementar una educación que eleve la integración de las TIC en el proceso de enseñanzaaprendizaje a nivel secundario. En este caso, Fernández Miravete (2018) en la región de Murcia. En este sentido, el autor analiza los resultados de 4 cursos académicos evaluando cinco dimensiones de las competencias digitales: Recursos digitales y grado de uso de las TIC en general; Conocimiento y uso de los recursos TIC; Cultura y respeto en el uso de la información digital; Acceso eficiente a la información; Niveles de uso y eficiencia en la comunicación de la información. Entre los resultados más relevantes se observa que más del $90 \%$ de los estudiantes incluidos en el grupo experimental llamado "digital" mejoraron bastante o mucho su competencia digital, siendo mejores los resultados respecto al grupo control o "no digital", especialmente en el acceso eficiente a la información, el uso de plataformas virtuales, entre otras.

Todas las metodologías y estrategias anteriores podrían resultar muy positivas para el desarrollo de las competencias estudiantiles en el contexto actual, siempre y cuando se logren insertar en un programa de enseñanza-aprendizaje que tenga en cuenta la semipresencialidad o la virtualidad, dada la situación de confinamiento en algunos países o regiones.

En este sentido, una estrategia conocida affective e-learning ha mostrado resultados satisfactorios en el desarrollo de estas competencias en los estudiantes. En este, se implementa un programa interuniversitario en modalidad semipresencial con un grupo de unidades didácticas hipermedia, en un modelo innovador e inclusivo de aprendizaje. Los autores, después de implementarlo observan resultados positivos en cuanto a las competencias digitales evaluadas, considerando que además el programa se adapta a los conocimientos previos y los distintos ritmos y estilos de aprendizaje de los alumnos. Así se observaron mejoras significativas en temas como "los derechos de autor, el uso de normas de internet, la interacción con diversas fuentes de internet, la gestión de la identidad digital, o la creación y edición de audios y vídeos, han obtenido una 
mejora en sus puntuaciones tras la realización del programa formativo" (Pérez García \& Hernández-Sánchez, 2020).

A lo anterior se debe sumar el enfoque pedagógico y metodológico innovador del modelo del Aula Invertida (Flipped classroom) que parece ajustarse muy bien al contexto actual del COVID19. En esta se invierten los roles educativos, donde el docente obtiene un papel más de moderador y guía del aprendizaje. Así, se reordenan las tareas, de modo que el estudiante adquiere los conceptos fuera de clase y en la misma se aclaran dudas y se aplican los contenidos en ambientes colaborativos de trabajo y a situaciones diversas (Hinojo Lucena et al., 2019), que bien podría ser la resolución de problemas, el trabajo en proyectos cooperativos y colaborativos, entre otros de los mencionados anteriormente.

El enfoque de la Clase Invertida, se puede entender como una metaestrategia o modelo aplicable perfectamente para conectar las TIC con las nuevas pedagogías necesarias para las aulas. Con este enfoque, el desarrollo de habilidades y competencias digitales es bidireccional, desde el docente en la creación de espacios y entornos creativos, colaborativos y cooperativos, en constante búsqueda y evaluación del contenido, su calidad, seguridad, etc., hasta el estudiante que es quien desarrolla estas habilidades para la consecución de sus objetivos cognitivos y a la vez comparte su diversidad creativa con el docente y sus compañeros, respetando las normas éticas del derecho de autor, entre otras. Sin embargo, para el desarrollo efectivo de este modelo, se requiere que los docentes puedan contar con competencias digitales básicas para implementarlo en un sistema educativo en línea o semipresencial (Andía Celaya et al., 2020).

Los resultados de Andía Celaya et al. (2020) indican que los docentes tienen dificultades sobre todo en las áreas competenciales directamente relacionadas con la implementación de la Clase Invertida como la comunicación y colaboración, así como con la creación de contenidos. En esta última área se debe notar que se considera por los autores como la más importante para desarrollar este tipo de metodologías. Así se observó que mientras los docentes pueden crear videos educativos con mayor o menor eficacia, los aspectos relacionados con la implementación de estrategias de aprendizaje lúdicas (gamificación), la creación de recursos educativos abiertos y el uso de herramientas digitales para la creación de evaluaciones, tienen puntajes inferiores a la media. Con estos resultados concuerda el trabajo de Pozo-Sánchez et al. (2020), en una muestra de 627 docentes los que se caracterizaron por presentar bajas competencias tecnopedagógicas que limitan la confianza de los profesores para implementar este modelo.

Entre las intervenciones experimentales destinadas a elevar las competencias digitales de los estudiantes mediante el Flipped Classroom, destaca el de Sosa Díaz y Palau Martín (2018) en jóvenes universitarios de Educación Infantil y Primaria. Los resultados indican una percepción de mejora significativa en competencias como la interpretación de información audiovisual, la creación y difusión de contenidos digitales, el análisis crítico del uso de las TIC, las estrategias didácticas para integrar las TIC en el aula, entre otras. Se observa además una buena percepción en el trabajo colaborativo entre los futuros docentes. Con esto concuerda la revisión sistemática realizada por Gómez-García et al. (2020), en la que se observa que, a pesar de las diversas metodologías para implementar el Aula Invertida en los grupos de alumnos y centros educativos, los estudiantes tienden a presentar mejoras significativas en competencias informacionales. 
Con lo anterior se puede reflexionar que mientras más se desarrollen las competencias digitales de los estudiantes, este modelo se irá haciendo cada vez más eficiente, redundando en una espiral de mejora continua, tanto en sus habilidades como en sus conocimientos.

\section{CONCLUSIONES}

La pandemia por la COVID 19 ha tenido importantes repercusiones a nivel global y se espera que continúen durante algún tiempo más. En este contexto, múltiples actividades económicas y sociales han pasado a desarrollarse en la virtualidad, comprendiendo los requerimientos de distanciamiento social que impone esta enfermedad. Entre estas actividades una de las más urgentes y al mismo tiempo más afectadas es en el ámbito educativo, donde se viene a acrecentar el problema de la brecha digital entre países pobres y ricos, y entre los diferentes estratos socioeconómicos de los países y comunidades.

A pesar de esto, esta situación ofrece una innegable oportunidad para reformular la educación, con la implementación, desarrollo y diseminación entre maestros y estudiantes de tecnologías que ayuden a alcanzar esa ansiada sociedad de la información y el conocimiento. Sin embargo, la bibliografía consultada refiere que tanto los docentes como los estudiantes, no tienen aún las competencias digitales desarrolladas como para hacer frente a esta digitalización cada vez más evidente de la sociedad.

Lo anterior también podría estar relacionado inicialmente con la amplia gama de términos que engloban en mayor o menor medida, las habilidades de los ciudadanos para llegar a insertarse en una sociedad de la información, la comunicación y el conocimiento. De este modo, las competencias digitales deben diferenciarse de otros como la alfabetización digital y la alfabetización informacional.

Aunque los aspectos distintivos de estos conceptos aún se debaten, se podría concluir que, mientras la alfabetización informacional se refiere sobre todo a cómo las personas gestionan la información de forma segura, creativa y responsable, y la alfabetización digital se enfoca más hacia las habilidades para la gestión de las TIC justamente para incluirse en esa sociedad de la información incluyendo a la primera y a otros tipos de alfabetizaciones digitales, las competencias digitales por su parte, se dirigen más hacia la comprensión de las dimensiones globales de estas tecnologías y su potencialidad transformadora de la sociedad, incluyendo así, los diferentes tipos de alfabetizaciones digitales. En este caso, podría ayudar el desarrollo de marcos conceptuales y dimensionales, así como la implementación estándares e indicadores para estudiar más a profundidad este tema.

Hasta el momento, los estudios tanto en docentes como en estudiantes revelan que estas competencias se encuentran en desarrollo. Asimismo, los datos apuntan a que, aunque los jóvenes hayan crecido y desarrollado en una sociedad digitalizada, eso no hace que tengan competencias digitales adecuadas. En esto influye de forma significativa la brecha digital, la que depende de factores socioeconómicos y políticos, impidiendo el acceso y capacitación eficiente en temas relacionados con las TIC.

Por lo anterior, el autor considera que deben implementarse programas tanto curriculares como profesionales, que fomenten el alcance de estas competencias, las que siempre irán evolucionando tal como se desarrollen las tecnologías que las requieran. Para ello, se necesita 
identificar, de acuerdo a cada realidad regional, nacional o local, cuáles son los estándares o competencias básicas que requieren los principales actores del proceso de Enseñanza-Aprendizaje para enfrentarse a los retos que imponen esta nueva realidad.

Entre estas metodologías, el Aula Invertida podría ser de mucha utilidad, puesto que puede integrar múltiples estrategias didácticas para lograr, no solo que los estudiantes de apropien o mejoren sus competencias digitales, sino que también es una oportunidad para los docentes de elevar su preparación tecnopedagógica. No obstante, se debe resaltar que esta metodología debe enfocarse cada vez más a procesos de evaluación continua no solo de los aprendizajes, sino también de los procesos de enseñanza-aprendizaje en sí mismos, mediante una retroalimentación oportuna tanto de los estudiantes como de los propios docentes que participan en este proceso.

Por lo anterior, el autor considera que, para implementar esta estrategia en un centro educativo, primero debe levantarse el estado actual de las competencias digitales y recursos informáticos y de acceso a la tecnología, tanto de estudiantes como de los docentes. A partir de identificar las deficiencias y de implementar estrategias de mejora, se podría lograr que este modelo no solo fluya en su versión más clásica, sino que avance hacia formas más innovadoras dentro de la educación virtual, semipresencial o a distancia donde el aprendizaje no se quede en el ámbito de un centro educativo, sino que apunte hacia toda la vida. De esta forma, el tema puede ser tan amplio como prolífico para los años venideros.

\section{Agradecimientos / Acknowledgments:}

Expresamos el agradecimiento a los docentes del Máster en Ciencias del Laboratorio Clínico de la Unidad de posgrado de la Universidad Politécnica Salesiana, Ecuador.

\section{Conflicto de intereses / Competing interests:}

Los autores declaran que no incurren en conflictos de intereses.

\section{Rol de los autores / Authors Roles:}

Dariel Díaz: conceptualización, curación de datos, análisis formal, adquisición de fondos, investigación, metodología, administración del proyecto, recursos, software, supervisión, validación, visualización, escritura - preparación del borrador original, escritura - revisar \& amp; edición.

Efraín Loyola: conceptualización, investigación, metodología, administración del proyecto, recursos, software, supervisión, validación, visualización, escritura - preparación del borrador original, escritura - revisar \& amp; edición.

\section{Fuentes de financiamiento / Funding:}

Los autores declaran que no recibieron un fondo específico para esta investigación.

\section{Aspectos éticos / legales; Ethics / legals:}

Los autores declaran no haber incurrido en aspectos antiéticos, ni haber omitido aspectos legales en la realización de la investigación.

\section{REFERENCIAS BIBLIOGRÁFICAS}

Acosta-Silva, D. A. (2017). Tras las competencias de los nativos digitales: avances de una metasíntesis. Revista Latinoamericana de Ciencias Sociales, Niñez y Juventud, 15(1), 471489. https://doi.org/10.11600/1692715x.1513014062016

Albertos, A., Domingo, A., \& Albertos, J. E. (2016). Estrategia docente para el desarrollo de la competencia digital en el aula universitaria: Del uso recreativo al uso formativo. Educar, 52(2), 243-261. https://doi.org/10.5565/rev/educar.732

Andía Celaya, L. A., Campión, R. S., \& Sota Eguizábal, J. M. (2020). ¿Estamos técnicamente 
preparados para el flipped classroom? un análisis de las competencias digitales de los profesores en españa. Contextos Educativos, 25, 275-311. https://doi.org/10.18172/con.4218

Botella Nicolás, A. M., \& Ramos Ramos, P. (2019). Investigación-acción y aprendizaje basado en proyectos. Una revisión bibliográfica. Perfiles Educativos, 41(163), 127-141. http://www.scielo.org.mx/scielo.php?pid=S0185-26982019000100127\&script=sci_arttext

Cabero-Almenara, J., \& Palacios-Rodríguez, A. (2020). Marco Europeo de Competencia Digital Docente «DigCompEdu». Traducción y adaptación del cuestionario «DigCompEdu CheckIn». Revista de Educación Mediática y TIC, 9(1), 213-234. https://doi.org/10.21071/edmetic.v9i1.12462

Cabezas González, M., Casillas Martín, S., Sanches Ferreira, M., \& Teixeira Diogo, F. L. (2017). Validación de un instrumento para medir la competencia digital de estudiantes universitarios (CODIEU) Validation of an instrument to measure the digital competence of university students (CODIEU). Revista de Estudios e Investigación en Psicología y Educación, Extr.(13), A13-022. https://doi.org/10.17979/reipe.2017.0.13.2180

Caena, F., \& Redecker, C. (2019). Aligning teacher competence frameworks to 21st century challenges: The case for the European Digital Competence Framework for Educators ( Digcompedu) . European Journal of Education, 54(3), 356-369. https://doi.org/10.1111/ejed.12345

Calvani, A., Fini, A., Ranieri, M., \& Picci, P. (2012). Are young generations in secondary school digitally competent? A study on Italian teenagers. Computer \& Education, 58(2), 797-807. https://doi.org/10.1016/j.compedu.2011.10.004

Carretero, S., Vuorikari, R., \& Punie, Y. (2017). DigComp 2.1: The Digital Competence Framework for Citizens with eight proficiency levels and examples of use. Union, Publications Office of the European. https://doi.org/10.2760/38842

Casillas, S., Cabezas, M., Ibarra, M. S., \& Rodríguez, G. (2017). Evaluation of digital competence from a gender perspective. Proceedings of the 5th International Conference on Technological Ecosystems for Enhancing Multiculturality, Part F1322, 1-5. https://doi.org/10.1145/3144826.3145372

CEPAL, \& UNESCO. (2020). La educación en tiempos de la pandemia de COVID-19. https://www.cepal.org/es/publicaciones/45904-la-educacion-tiempos-la-pandemia-covid-19

Chan, B., Churchill, D., \& Chiu, T. (2017). Digital Literacy Learning In Higher Education Through Digital Storytelling Approach. Journal of International Education Research, 13(1), 1-16. https://files.eric.ed.gov/fulltext/EJ1144564.pdf

Coldwell-Neilson, J. (2017). Assumed digital literacy knowledge by Australian universities: Are students informed? ACE '17: Proceedings of the Nineteenth Australasian Computing Education Conference, 75-80. https://doi.org/10.1145/3013499.3013505

Dias-Trindade, S., Moreira, J. A., \& Gomes Ferreira, A. (2020). Assessment of university teachers on their digital competences. Assessment of University Teachers / QWERTY, 15(1), 50-69. https://doi.org/10.30557/QW000025

Domingo-Coscolla, M., Bosco-Paniagua, A., Carrasco-Segovia, S., \& Valero-Valero, J. A. (2020). Fomentando la competencia digital docente en la universidad: Percepción de estudiantes y docentes. Revista de Investigación Educativa, 38(1), 167-782. https://doi.org/10.6018/rie.340551 
Carrillo-García, M.E., Cascales-Martínez, A., \& López Valero, A. (2018). Apps para el aprendizaje de idiomas en la Universidad de Murcia. RED. Revista de Educación a Distancia., 58. https://doi.org/10.6018/red/58/13

Equipo técnico Encuesta Nacional Multipropósito de Hogares. (2020). Encuesta de seguimiento al Plan Nacional de Desarrollo. Indicadores de tecnología de la información y la comunicación. (No. 02). https://www.ecuadorencifras.gob.ec/documentos/webinec/Estadisticas_Sociales/TIC/2019/201912_Boletin_Multiproposito_TIC.pdf

Espada, M., Rocu, P., Navia, J. A., \& Gómez-López, M. (2020). Rendimiento académico y satisfacción de los estudiantes universitarios hacia el método flipped classroom. Profesorado, Revista de Currículum y Formación Del Profesorado, 24(1), 116-135. https://doi.org/10.30827/profesorado.v24i1.8710

Esteve-Mon, F. M., Gisbert-Cervera, M., \& Lázaro-Cantabrana, J. L. (2016). La competencia digital de los futuros docentes: ¿Cómo se ven los actuales estudiantes de educación? Perspectiva Educacional, 55(2), 38-54. https://doi.org/10.4151/07189729-Vol.55-Iss.2Art.412

Falcó Boudet, J. M. (2017). Evaluación de la competencia digital docente en la Comunidad Autónoma de Aragón. Revista Electrónica de Investigación Educativa, 19(4), 73. https://doi.org/10.24320/redie.2017.19.4.1359

Fernández-Cruz, F.-J., \& Fernández-Díaz, M.-J. (2016). Los docentes de la Generación Z y sus competencias digitales. Comunicar, 24(46), 97-105. https://doi.org/10.3916/C46-2016-10

Fernández Miravete, Á. D. (2018). La competencia digital del alumnado de educación secundaria en el marco de un proyecto educativo TIC (1:1). Edutec. Revista Electrónica De Tecnología Educativa, 63, 60-72. https://doi.org/10.21556/edutec.2017.63.1027

Flores-Lueg, C., \& Roig Vila, R. (2016). Percepción de estudiantes de Pedagogía sobre el desarrollo de su competencia digital a lo largo de su proceso formativo. Estudios Pedagógicos, 42(3), 129-148. https://doi.org/http://dx.doi.org/10.4067/S071807052016000400007

Formichella, M. M., Alderete, M. V., \& Krüger, N. (2020). Efecto de las TIC sobre los resultados educativos: estudio en barrios vulnerables de Bahía Blanca. Ciencia, Docencia y Tecnología, 31(61), 120-144. https://doi.org/10.33255/3161/736

García Fernández, N., Rivero Moreno, M. L., \& Ricis Guerra, J. (2020). Brecha digital en tiempo del COVID-19. Hekademos: Revista Educativa Digital, 28, 76-85. https://dialnet.unirioja.es/servlet/articulo?codigo $=7602854$

Gisbert Cervera, M., González Martínez, J., \& Esteve Mon, F. M. (2016). Competencia digital y competencia digital docente: una panorámica sobre el estado de la cuestión. Revista Interuniversitaria de Investigación En Tecnología Educativa, 74-83. https://doi.org/10.6018/riite2016/257631

Gómez-García, G., Hinojo-Lucena, F.-J., Cáceres-Reche, M.-P., \& Ramos Navas-Parejo, M. (2020). The Contribution of the Flipped Classroom Method to the Development of Information Literacy: A Systematic Review. Sustainability, 12(18), 7273. https://doi.org/10.3390/su12187273

González Calatayud, V., Román García, M., \& Prendes Espinosa, M. P. (2018). Formación en competencias digitales para estudiantes universitarios basada en el modelo DigComp. Edutec. Revista Electrónica de Tecnología Educativa, 65, 1-15. 
https://doi.org/10.21556/edutec.2018.65.1119

Henriquez-Coronel, P., Gisbert Cervera, M., \& Fernández Fernández, I. (2018). La evaluación de la competencia digital de los estudiantes: una revisión al caso latinoamericano. Chasqui. Revista Latinoamericana de Comunicación, 137, 93-112. https://doi.org/10.16921/chasqui.v0i137.3511

Hinojo Lucena, F. J., Aznar Díaz, I., Romero Rodríguez, J. M., \& Marín Marín, J. A. (2019). Influencia del aula invertida en el rendimiento académico. Una revisión sistemática. Campus Virtuales, $8(1)$ 9-18. http://uajournals.com/ojs/index.php/campusvirtuales/article/view/384/300

INDEC. (2020). Tecnología. Informes técnicos. INDEC: Instituto Nacional de Estadística y Censos de La República Argentina. https://www.indec.gob.ar/indec/web/Nivel3-Tema-4-26

INEGI. (2018). Encuesta Nacional sobre Disponibilidad y Uso de Tecnologías de la Información en los Hogares (ENDUTIH) 2018. Instituto Nacional de Estadística y Geografía. https://www.inegi.org.mx/programas/dutih/2018/

IX Encuesta de Acceso y Usos de Internet. (2017). https://www.subtel.gob.cl/wpcontent/uploads/2018/07/Informe_Final_IX_Encuesta_Acceso_y_Usos_Internet_2017.pdf

Karsenti, T., Poellhuber, B., Parent, S., \& Michelot, F. (2020). What is the Digital Competency Framework? International Journal of Technologies in Higher Education, 17(1), 11-14. https://doi.org/10.18162/ritpu-2020-v17n1-04

Koelling, G., \& Townsend, L. (2019). Research clinics: An alternative model for large-scale information literacy instruction. Communications in Information Literacy, 13(1), 75-90. https://doi.org/10.15760/comminfolit.2019.13.1.6

Kolle, S. R. (2017). Global research on information literacy: a bibliometric analysis from 2005 to 2014. The Electronic Library, 35(2), 283-298. https://doi.org/10.1108/EL-08-2015-0160

Crawford-Visbal, J. L., Crawford-Tirado, L., Zoraida Ortiz-Záccaro, Z., \& Abalo, F. (2020). Assessment of Digital Competences in Communication Students across four Latin American Universities. Education in the Knowledge Society, 21, 1-14. https://doi.org/10.14201/eks.19112

Lloyd, M. (2020). Desigualdades educativas y la brecha digital en tiempos de COVID-19. In H. CasanovaCardiel, Á. Díaz-Barriga, L. Pérez Fuentes, \& S. Plá (Eds.), Educación y pandemia: una visión académica (1a ed., pp. 115-121). Universidad Autónoma de México. http://www.iisue.unam.mx/nosotros/covid/educacion-y-pandemia

López-Meneses, E., Sirignano, F. M., Vázquez-Cano, E., \& Ramírez-Hurtado, J. M. (2020). University students' digital competence in three areas of the DigCom 2.1 model: A comparative study at three European universities. Australasian Journal of Educational Technology, 36(3), 69-88. https://doi.org/10.14742/AJET.5583

López Núñez, J. A., Campos Soto, M. N., Aznar Díaz, I., \& Rodríguez Jiménez, C. (2020). Competencia digital del profesorado para la atención al alumnado con dificultades de aprendizaje. Una revisión teórica. Revista Electronica Interuniversitaria de Formacion del Profesorado, 23(2), 143-154. https://doi.org/10.6018/reifop.419171

Lucas, M. (2019). Facilitating Students' Digital Competence: Did They Do It? In M. Scheffel, J. Broisin, V. Pammer-Schindler, A. Ioannou, \& J. Schneider (Eds.), Transforming Learning with Meaningful Technologies. EC-TEL 2019. Lecture Notes in Computer Science (Vol. 
11722, pp. 3-14). Springer Verlag. https://doi.org/10.1007/978-3-030-29736-7_1

Machin-Mastromatteo, J. D. (2012). Participatory action research in the age of social media: literacies, affinity spaces and learning. New Library World, 113(11/12), 571-585. https://doi.org/10.1108/03074801211282939

Maciá Bordalba, M., \& Garreta Bochaca, J. (2018). Accesibilidad y alfabetización digital: Barreras para la integración de las TIC en la comunicación familia/escuela. Revista de Investigacion Educativa, 36(1), 239-257. https://doi.org/10.6018/rie.36.1.290111

Martínez Navarro, J. A. (2020). La competencia digital de los estudiantes universitarios latinoamericanos. IJERI: International Journal of Educational Research and Innovation, 14(14), 276-289. https://doi.org/10.46661/ijeri.4387

Mendoza-Ruano, J. J., \& Caldera-Serrano, J. (2014). Umbrales para la determinación de la brecha digital: Comparativa entre regiones desarrolladas. Transinformacao, 26(2), 125-132. https://doi.org/10.1590/0103-37862014000200002

Mishra, K. E., Wilder, K., \& Mishra, A. K. (2017). Digital literacy in the marketing curriculum: Are female college students prepared for digital jobs? Industry and Higher Education, 31(3), 204-211. https://doi.org/10.1177/0950422217697838

Ocaña-Fernández, Y., Valenzuela-Fernández, L., \& Morillo-Flores, J. (2020). La competencia digital en el docente universitario. Propósitos y Representaciones, 8(1), e455. https://doi.org/10.20511/pyr2020.v8n1.455

ONU. (2020). El impacto del COVID-19 en la educación podría desperdiciar un gran potencial humano y revertir décadas de progreso. NOTICIAS ONU. https://news.un.org/es/story/2020/08/1478302

Pascual, M. A., Ortega-Carrillo, J. A., Pérez-Ferra, M., \& Fombona, J. (2019). Competencias Digitales en los Estudiantes del Grado de Maestro de Educación Primaria. El caso de tres Universidades Españolas. Formación Universitaria, 12(6), 141-150. https://doi.org/10.4067/S0718-50062019000600141

Pérez-Escoda, A., Iglesias-Rodríguez, A., Meléndez-Rodríguez, Lady, \& Berrocal-Carvajal, V. (2020). Competencia digital docente para la reducción de la brecha digital: Estudio comparativo de España y Costa Rica Teacher's Digital Competence for Reducing Digital Divide: Comparative Study Between Spain and Costa Rica. Tripodos, 46, 77-96. http://www.tripodos.com/index.php/Facultat_Comunicacio_Blanquerna/article/view/790

Pérez-Rodríguez, A., Delgado-Ponce, A., Marín-Mateos, P., \& Romero-Rodríguez, L. M. (2019). Media competence in Spanish secondary school students. Assessing instrumental and critical thinking skills in digital contexts. Educational Sciences: Theory and Practice, 19(3), 33-48. https://doi.org/10.12738/estp.2019.3.003

Pérez García, Á., \& Hernández-Sánchez, A. M. (2020). Efectos del programa affective e-learning en el desarrollo de la Competencia Digital en estudiantes del Grado en Educación Primaria. Educatio Siglo XXI, 38(3), 129-150. https://doi.org/10.6018/educatio.416431

Pinto, M., \& Uribe-Tirado, A. (2017). Presencia de la formación en competencias informacionales (Alfin) en las bibliotecas nacionales iberoamericanas. Investigación Bibliotecológica, 31(71), 73-102. https://doi.org/10.22201/iibi.0187358xp.2017.71.57811

Pozo-Jara, A. (2017). La alfabetización informacional y la alfabetización informática: ¿iguales o diferentes?

Dominio de Las

Ciencias,

$3(3)$,

689-713. 
https://dominiodelasciencias.com/ojs/index.php/es/article/view/625

Pozo-Sánchez, S., López-Belmonte, J., Rodríguez-García, A. M., \& López-Núñez, J. A. (2020). Teachers' digital competence in using and analytically managing information in flipped learning. Cultura $\quad y \quad$ Educacion, 32(2), 213-241. https://doi.org/10.1080/11356405.2020.1741876

Prendes-Espinosa, M.-P., Castañeda-Quintero, L., \& Gutiérrez-Porlán, I. (2010). ICT competences of future teachers. Comunicar, XVIII(35), 175-182. https://doi.org/10.3916/C35-2010-03-11

RAE. (2014). Competencia. In Diccionario de la Real Academia Española (23a ed.). Asociación de Academias de la Lengua Española (ASALE).

Rangel Baca, A. (2015). Competencias docentes digitales: propuesta de un perfil. Píxel-Bit, Revista de Medios y Educación, 46, 235-248. https://doi.org/10.12795/pixelbit.2015.i46.15

Revelo-Rosero, J. E., Vinicio Lozano, E., \& Bastidas Romo, P. (2019). La competencia digital docente y su impacto en el proceso de enseñanza-aprendizaje de la matemática. Espirales Revista Multidisciplinaria de Investigación, 3(28), 156-175. https://doi.org/10.31876/er.v3i28.630

Rodicio-García, M. L., Ríos-De-Deus, M. P., Mosquera-González, M. J., \& Penado Abilleira, M. (2020). La Brecha Digital en Estudiantes Españoles ante la Crisis de la Covid-19. Revista Internacional de Educacion Para La Justicia Social, 9(3), 103-125. https://doi.org/10.15366/RIEJS2020.9.3.006

Sá, M. J., \& Serpa, S. (2020). COVID-19 and the promotion of digital competences in education. Universal Journal of Educational Research, 8(10), 4520-4528. https://doi.org/10.13189/ujer.2020.081020

Sales, D. (2020). Definition of information literacy 2018. Anales de Documentacion, 23(1), 1-5. https://doi.org/10.6018/analesdoc.373811

Sánchez-Caballé, A., Gisbert-Cervera, M., \& Esteve-Mon, F. (2020). The digital competence of university students: a systematic literature review. Aloma: Revista de Psicologia, Ciències de $\begin{array}{lllll}\text { l'Educació } \quad i & \text { de } & \text { l'Esport, } & \text { 63-74. }\end{array}$ http://revistaaloma.net/index.php/aloma/article/view/388

Sánchez Marrero, O., Amar Mohamed, R., \& Triadú Xifra, J. (2019). Tratamiento de la información y la competencia digital de los estudiantes para la producción de géneros discursivos en la Universidad Ecotec (Ecuador). Espacios, 40(15), 14-25. http://www.revistaespacios.com/a19v40n15/a19v40n15p14.pdf

Silva, J., Usart, M., \& Lázaro-Cantabrana, J. L. (2019). Competencia digital docente en estudiantes de último año de Pedagogía de Chile y Uruguay. Comunicar, 27(61), 31-40. https://doi.org/10.3916/C61-2019-03

Slavova, L., \& Garov, K. (2019). Increasing the Digital Competences of Students. Mathematics and Informatics, 62(1), 43-52. content/uploads/2019/03/azbuki.bg_dmdocuments_Math_Info_1_19_Slavova_Garov.pdf

Solís de Ovando Calderón, J., \& Jara Jara, V. (2019). Competencia digital de docentes de ciencias de la salud de una universidad chilena. Píxel-BIT Revista de Medios y Educación, 56, 193211. https://doi.org/https://doi.org/10.12795/pixelbit.2019.i56.10

Sosa Díaz, M. J., \& Palau Martín, R. F. (2018). Flipped classroom para adquirir la competencia digital docente: una experiencia didáctica en la Educación Superior. Pixel-Bit, Revista de 
Medios y Educacion, 52, 37-54. https://doi.org/10.12795/pixelbit.2018.i52.03

Spante, M., Hashemi, S. S., Lundin, M., \& Algers, A. (2018). Digital competence and digital literacy in higher education research: Systematic review of concept use. In Cogent Education (Vol. 5, Issue 1, pp. 1-21). Taylor and Francis Ltd. https://doi.org/10.1080/2331186X.2018.1519143

Sturges, P., \& Gastinger, A. (2012). La alfabetización informacional como derecho humano. Anales de Documentación, 15(1), 1-14. https://doi.org/10.6018/analesdoc.15.1.147651

Tagge, N. (2018). Leveraging accreditation to integrate sustainable information literacy instruction into the medical school curriculum. Journal of the Medical Library Association, 106(3), 377382. https://doi.org/10.5195/jmla.2018.276

Tang, C. M., \& Chaw, L. Y. (2016). Digital Literacy: A Prerequisite for Effective Learning in a Blended Learning Environment? The Electronic Journal of E-Learning, 14(1), 54-65. https://files.eric.ed.gov/fulltext/EJ1099109.pdf

UNESCO. (2019). Marco de competencias de los docentes en materia de TIC. UNESCO Biblioteca Digital. https://unesdoc.unesco.org/ark:/48223/pf0000371024?fbclid=IwAR1Fl_5c4W9G206eh5A AMkcc-PGXx2QT3PBx1mVETRcjTlvC_yEZErXmrYI

Vázquez-Cano, E., Reyes Vélez, M., Colmenares Zamora, L., \& López Meneses, E. (2017). Competencia digital del alumnado de la Universidad Católica de Santiago de Guayaquil Dialnet. Opción: Revista de Ciencias Humanas y Sociales, 83, 229-251. https://dialnet.unirioja.es/servlet/articulo?codigo $=6228337$

Vidal Ledo, M., Fernández Valdés, M. de las M., Zayas Mujica, R., \& Paredes Esponda, E. (2016). Alfabetización Informacional. Educación Médica Superior, 30(4). http://www.ems.sld.cu/index.php/ems/article/view/924

Yépez-Reyes, V. (2018). Analfabetismo digital: una barrera para las narrativas transmedia y el diálogo social al margen de la industria cultural. Razón y Palabra, 22(2_101), 285-301. https://www.revistarazonypalabra.org/index.php/ryp/article/view/1203 